
\title{
25 Research Soure \\ Complement Factor H-Related 3 induces inflammation and complosome activation in human RPE cells
}

Nicole Schäfer

University Hospital Regensburg: Universitatsklinikum Regensburg

Anas Rasras

Al-Blaqa Applied University

Delia Ceteras

University Hospital Regensburg: Universitatsklinikum Regensburg

Sabine Amslinger

University of Regensburg: Universitat Regensburg

Volker Enzmann

University of Bern: Universitat Bern

Herbert Jägle

University Hospital Regensburg: Universitatsklinikum Regensburg

Diana Pauly ( $\nabla$ diana.pauly@uni-marburg.de )

Philipps-University Marburg https://orcid.org/0000-0002-1563-1601

\section{Research}

Keywords: AMD, complement activation, complosome, FHR-3, immune therapy, inflammation, internalization, oxidative stress epitopes, RETC-2, RPE cells

Posted Date: April 1st, 2021

DOl: https://doi.org/10.21203/rs.3.rs-344659/v1

License: (a) (1) This work is licensed under a Creative Commons Attribution 4.0 International License. Read Full License 


\section{Abstract}

Background Complement Factor H-Related 3 (FHR-3) is a major regulator of the complement system, which is associated with different diseases, such as age-related macular degeneration. The noncanonical local, cellular functions of FHR-3 remained poorly understood.

Methods Human retinal pigment epithelium (RPE) cells (ARPE-19 cells and primary human RPE cells (hpRPE)), cultivated in Transwell ${ }^{\circledR}$ inserts, were apically treated with either FHR-3 alone or with the chimerized monoclonal anti-FHR-3 antibody RETC-2-ximab, or with FHR-1, FH, Properdin or not treated for 5 - 24 h, respectively. Interaction of FHR-3 with oxidative stress epitopes was determined by ELISA. Internalization studies of FHR-3 or FH by ARPE-19 cells was determined by immunofluorescence live cell imaging. Impact of FHR-3 on RPE cell-specific complement components and inflammation markers were analyzed on mRNA (RT-qPCR) and on protein level (Western Blot, ELISA, protein secretion assays, immunofluorescence).

Results Here, we report that FHR-3 bound to oxidative stress epitopes and competed with FH for interaction. Furthermore, FHR-3 was internalized by senescent viable RPE cells and modulated timedependently complement component (C3, CFB) and receptor (C3aR, CR3) expression of human RPE cells. Independently of any external blood-derived proteins, complement activation products were detected. Anaphylatoxin C3a was visualized in treated cells and showed a translocation from the cytoplasm to the cell membrane after FHR-3 exposure. Subsequently, FHR-3 induced a RPE cell dependent proinflammatory micro-environment. Inflammasome NLRP3 activation and pro-inflammatory cytokine secretion of IL-1ß, IL-18, IL-6 and TNF-a were induced after FHR-3-RPE interaction. Additionally, important pattern recognition molecules of the innate immune system, Toll-like receptors 1 and 3 , as well as proteasome subunits were impaired in RPE cells after FHR-3 incubation. A chimerized monoclonal antiFHR-3 antibody, RETC-2-ximab, ameliorated the effect of FHR-3 on ARPE-19 cells.

Conclusion Our studies suggest FHR-3 as an exogenous trigger molecule for the RPE cell complosome and as a productive target for a new therapeutic approach using RETC-2-ximab for associated degenerative diseases.

\section{Background}

Studied for more than one century, but still not fully understood - the evolutionary ancient complement system, is one of the first defense lines of our body to protect from pathogens, cellular debris or dead cells. The complement system is tightly regulated to prevent dysregulation leading to progression of different degenerative diseases such as age-related macular degeneration (AMD) (1). One major group of soluble regulators are complement factor $\mathrm{H}(\mathrm{FH})$, its splice variant factor $\mathrm{H}$-like protein 1 (FHL-1), and its related proteins $1-5($ FHR-1 - 5) (2-4). Single nucleotide polymorphisms (SNP) located in the complement factor $\mathrm{H}$ (CFH) gene locus have been described to be responsible for AMD pathology $(5,6)$. While the most relevant CFHSNP (Y402H) contributed to AMD progression, a joint deletion of the 
complement factor-H related 3 and $1(\triangle C F H R 3 / 1)$ genes was protective for the disease $(7,8)$. FHR- 1 and FHR-3 are mainly produced by hepatocytes and released into the systemic circulation. Besides the local expression of FH and FHL-1 by retinal pigment epithelium (RPE) cells (9), FHR3 is also produced by retinal macrophages/microglia cells (10).

In the eye, macrophages/microglia and RPE cells are important to maintain the physiological homeostasis of the neuronal tissue. The RPE forms the outer blood-retinal barrier isolating the retina from the systemic immune system. Besides absorption of light and protection against photo-oxidation, the RPE supports the retina by secretion of various nutrients, which is precisely regulated. However, during AMD progression age-dependent disruption and loss of RPE cells occurs $(11,12)$. This is accompanied by loss of RPE function e.g. failure to degrade proteins, inflammaging or increased cellular oxidative stress $(13,14)$.

Oxidative stress can lead to structural modifications resulting in novel oxidation-specific epitopes (OSE) detected in RPE cells $(15,16)$. OSE can trigger inflammation in the retina, which was inhibited by FH binding $(17,18)$. FHR-1 and FHR-3 also attach to OSE on senescent cells and compete with FH for binding (19). This interference of FHR1 and FHR-3 prevents FH-mediated proteolysis of the central complement component $\mathrm{C} 3$ into iC $3 \mathrm{~b}$ and results in enhanced activity of the soluble complement system (20).

Besides its blood-related function, $\mathrm{FH}$ also acts on intracellular complement components, the so called "complosome" $(21,22)$. FH is internalized by stressed and apoptotic RPE cells $(18,21)$, resulting in reduced endogenous C3-cleavage and increased cell survival in stressed cells (18), but contrary increased C3b-fragments are detected in apoptotic RPE cells, facilitating RPE cell opsonization (21). A similar interaction was also described for FHR-1 on necrotic cells, including RPE cells, but a cellular incorporation of FHR-1 hadn't been reported $(20,23)$. Cellular FHR-1 interaction increases complement activation as well as deposition of C3 and C4 fragments on cell surfaces $(23,24)$. Further, inflammasome reactivity is triggered on monocytes by FHR-1 binding but not upon FHR-3 interaction (20).

In RPE cells, inflammasome activation is so far mainly related to stress and complement receptor signaling (25-27), but not to FHR-binding. RPE cells autonomously produce and activate numerous complement components independently from blood-derived complement proteins $(26,27)$, which can than bind to complement receptors. This local complement expression and secretion by RPE cells is modulated by external stress (27-31). Stress-related activation of the inflammasome is associated with a pro-inflammatory secretion phenotype of RPE cells $(25,30,32,33)$, which in return correlates with complement activation (30).

However, a direct effect of FHR-3 on RPE cellular physiology and its non-canonical functions modulating the complosome has not been described so far. Knowing that FHR-3 is expressed by retinal macrophages/microglia in a degenerated human retina (10), we sought to explore the functional role of apical FHR-3 on RPE cells in depth. Here, we describe a novel local function of FHR-3 as an exogenous danger molecule for RPE cells, sensing those cells for complosome activation independent of other 
extracellular complement sources and inducing inflammatory immune responses, increased epithelialmesenchymal transition (EMT), decreased proteasome pathway and altered toll-like receptors. This effect was attenuated by blocking FHR-3 using a specific chimerized monoclonal antibody RETC2-ximab.

\section{Methods}

\subsection{Human Material and Ethical Statements}

The research complies with the human research act (HRA) stating that small quantities of bodily substances removed in the course of transplantation may be anonymized for research purposes without consent (HRA Chap. 5, paragraph 38, Switzerland). Human primary retinal pigment epithelial cells (hpRPE) were prepared from two anonymized donor eyes as previously described (34).

Complement-depleted human sera were purchased from Complement Technology. All human serum samples were stored at $-80^{\circ} \mathrm{C}$.

\subsection{PCR for genetic analysis}

DNA was isolated from human adult retinal pigment epithelium cells (ARPE-19 cells, American Type Culture Collection, \#CRL-2302) lysates and sclera slices of donor eyes using ReliaPrep ${ }^{\text {TM }}$ FFPE gDNA Miniprep System (Promega, Mannheim, Germany, \#A2351). PCR amplification of relevant AMDassociated complement SNPs was performed using in-house generated primers (Table S 1) and the following cycle steps, according to the MIQE guidelines: denaturation $\left(95^{\circ} \mathrm{C}, 1 \mathrm{~min}\right)$, annealing $\left(60^{\circ} \mathrm{C}, 1\right.$ min), elongation $\left(72^{\circ} \mathrm{C}, 1 \mathrm{~min}\right), 33$ cycles. Afterwards, DNA-sequencing was performed by GeneArt (Thermo Fisher Scientific, Dreieich, Germany) using either forward or reverse in-house primers, respectively (Table $\mathbf{S} 1$ ).

\subsection{Cell Culture and Treatment}

ARPE-19 cells (passage 38) were cultivated in cell culture flasks with DMEM/F12 (Sigma Aldrich, Munich, Germany), $10 \%$ foetal calf serum (FCS; PanBiotech, Aidenbach, Germany) and $1 \%$ penicillin/streptomycin until they reached confluency of approx. $80 \%\left(37^{\circ} \mathrm{C}, 5 \% \mathrm{CO}_{2}\right)$. Afterwards, cells were cultivated in Transwell® inserts for 4-6 weeks, as published previously (30). hpRPE cells were harvested from the eyecup after enzymatic digestion and centrifuged at $259 \times \mathrm{g}$ for $5 \mathrm{~min}$ at $4^{\circ} \mathrm{C}$. Cells were cultivated in Dulbecco's modified Eagle's medium/ Nutrient Mixture F-12 (DMEM/F-12 GlutaMax, Thermo Fisher Scientific, \#31331-028) containing 5 \% FCS (Thermo Fisher Scientific, \#10500-064), 1 \% PenicillinStreptomycin (Thermo Fisher Scientific, \#15070-063), 1 \% N1 Medium Supplement (Merck, Darmstadt, Germany, \#N6530), 10 mM MEM on-essential amino acids (Thermo Fisher Scientific, \#11140-035), 0.25 $\mathrm{mg} / \mathrm{ml}$ taurine (Merck, \#T0625), $4.5 \mathrm{mg} / \mathrm{ml}$ glucose solution (Thermo Fisher Scientific, \#G524940-01), $0.013 \mathrm{ng} / \mathrm{ml}$ triiodothyronine (Merck, \#T2877), $0.02 \mu \mathrm{g} / \mathrm{ml}$ hydrocortisone (Merck, \#H0888), $20 \mathrm{ng} / \mathrm{ml}$ human basic growth factor (hbFGF, R\&D Systems, Minneapolis, MN, USA, \#13256029), and $1 \mathrm{mg} / \mathrm{ml}$ human epidermal growth factor (hEGF, Thermo Fisher Scientific, \#PHG0311) in laminin-coated Transwell $\circledast$ inserts under standard conditions $\left(37^{\circ} \mathrm{C}, 5 \% \mathrm{CO}_{2}, 80 \%\right.$ humidity). 
Polarized ARPE-19 cells and hpRPE cells were treated apically with either $50 \mu \mathrm{g} / \mathrm{ml}(1 \mu \mathrm{M})$ FHR-3-strep (recombinant, in-house) (10), FHR-1-strep (recombinant, in-house), FH (native, Complement Technology, Tyler, TX, USA, \#A137) or FP (native, Complement Technology, \#A139) for 5,12 or $24 \mathrm{~h}$, or with $50 \mu \mathrm{g} / \mathrm{ml}$ $(1 \mu \mathrm{M})$ FHR-3 and $150 \mu \mathrm{g} / \mathrm{ml}(1 \mu \mathrm{M})$ anti-FHR-3 RETC-2-ximab (recombinant, in-house) or anti-BSA control-ximab (recombinant, in-house) for $5 \mathrm{~h}$.

\subsection{Immunofluorescence}

Polarized ARPE-19 cells in Transwell® inserts were permeabilized (PBS/0.2\% Tween20 (PBS-T), 45 min) and paraformaldehyde-fixated (4\%, $20 \mathrm{~min})$. Afterwards, unspecific binding was blocked (3\% bovine serum albumin (BSA)/PBS-T, $1 \mathrm{~h}$ ). Antigens were detected using specific primary antibodies (3\% BSA/PBS-T, overnight): anti-C3 (Abcam, Cambridge, UK, \#ab181147), anti-C3a des Arg (Hycult, Uden, Netherlands, \#HM2074), anti-CFB (Merck, \#341272), anti-C3aR (Antibodies-online, Aachen, Germany, \#ABIN682213), anti-CD11b (Biorbyt, Cambridge, UK, \#orb19554), anti-FHR-3 (RETC-2, in-house), antiGM130 (R\&D Systems, \#AF8199-SP) and anti-ZO-1 (Thermo Fisher Scientific, \#61-7300). Fluorescenceconjugated secondary antibodies for detection were the following (3\% BSA/PBS, $45 \mathrm{~min}$ ): anti-mouse IgG488 (Jackson ImmunoResearch, West Grove, PA, USA, \#715-545-150), anti-mouse IgG-Cy3 (Jackson ImmunoResearch, \#715-165-150), anti-goat IgG-Cy3 (Jackson ImmunoResearch, \#305-035-003), antirabbit IgG-488 (Jackson ImmunoResearch, \#711-545-152), GAPDH-HRP (Cell Signaling Technology, Beverly, MA, USA, \#3683). The fluorochrome HOECHST 33342 (Thermo Fisher Scientific, \#H3570) was used to stain DNA and acti-stain ${ }^{\text {TM }} 488$ phalloidin (Cytoskeleton, Denver, CO, USA, \#PHDG1-A) detected specifically actin filaments in ARPE-19 cells. Cells were covered with fluorescence mounting medium (Dako, Agilent Technologies, Boeblingen, Germany, \#S302380-2). Images were taken with a VisiScope CSU-X1 Confocal System (Visitron Systems, Puchheim, Germany) and a high-resolution sCMOS camera, and further processed with Adobe Photoshop CC 2019.

FHR-3 labelling for internalization studies was performed using pHrodo ${ }^{\mathrm{TM}}$ Red Microscale Labeling Kit (Thermo Fisher Scientific, \#P35363) according to the manufacturer's protocol. Labelled FHR-3 (FHR-3pHrodo) was incubated apically on ARPE-19 cells for 60 min, cells were then fixed with paraformaldehyde (4\%, 20 min). Internalized FHR-3 was detected immunohistologically by means of a Leica AF6000LX fluorescence microscope, equipped with a Leica DFC350 FX digital camera. The images were visualized by 3D modeling using Leica deconvolution software module, and further processed with Adobe Photoshop CC 2019.

\subsection{Transepithelial Resistance (TER) and Cellular Capacitance $\left(\mathrm{C}_{\mathrm{Cl}}\right)$}

TER, a measure of cell monolayer barrier function, and $\mathrm{C}_{\mathrm{Cl}}$, an indicator of the expression of membrane folding such as microvilli, of polarized ARPE-19 cells were recorded online using the established cellZscope device (nanoAnalytics, Münster, Germany), as described previously (30).

\subsection{RT-qPCR}

RNA was isolated using a NucleoSpin® RNA/Protein kit (Macherey-Nagel, Düren, Germany). Samples quality and purity were ensured by randomly testing using QIAxcel® RNA analyses (Qiagen, Hilden, 
Germany). Purified mRNA was transcribed into cDNA with a QuantiTect ${ }^{\circledR}$ Reverse Transcription Kit (Qiagen, \#205313). Transcripts of complement components, receptors, and inflammation-associated markers were analyzed using a Rotor-Gene SYBR ${ }^{\circledR}$ Green PCR Kit either with QuantiTect Primer Assays (Qiagen, Table S 1) or in-house-designed primer pairs (Metabion, Planegg, Germany, Table S 1) in a Rotor Gene Q 2plex cycler (Qiagen), using the following conditions: hold $\left(95^{\circ} \mathrm{C}, 5 \mathrm{~min}\right)$, cycling $\left(95^{\circ} \mathrm{C}, 5 \mathrm{sec}\right.$; $\left.60^{\circ} \mathrm{C}, 10 \mathrm{sec} ; 72^{\circ} \mathrm{C}, 20 \mathrm{sec} ; 40 \mathrm{cycles}\right)$. Data were normalized to $G A P D H$ housekeeper expression, analysed by using the $2^{-\triangle \triangle C T}$ method. Values were depicted on a linear scale using $\log _{2}$-transformed scores to equally visualize increases and decreases in expression levels.

\subsection{Synthesis of 2-( $\omega$-Carboxyethyl) pyrrole bovine serum albumin (CEP-BSA)}

CEP-BSA was prepared using a method by Lu et al. (35), which was shortened by one step using succinic anhydride together with the Grignard reagent of 2-(2-bromoethyl)-1,3-dioxane to get directly 6-(1,3-dioxan2-yl)-4-oxohexanoic acid in $57 \%$ yield.

The pyrrole content in CEP-BSA was determined by Ehrlich assay using the Ehrlich reagent 4(dimethylamino)benzaldehyde and 3-(1-methyl-1H-pyrrol-2-yl)propanoic acid (Sigma Aldrich) as the pyrrole standard measuring the absorbance of the formed pyrrole adduct at $540 \mathrm{~nm}$.

\subsection{ELISA for oxidative stress epitopes-interaction}

MaxiSorp microtiter plates (Nalgene Nunc, Rochester, NY, USA) were coated either with CEP-BSA, malondialdehyde (MDA)-BSA (Hölzel Diagnostika, Köln, Germany, \#20P-MD-BS102) or malondialdehydeacetaldehyde (MAA)-BSA (10 $\mu \mathrm{g} / \mathrm{ml}$, PBS, overnight, $\left.4^{\circ} \mathrm{C}\right)$. Blocking was performed with PBS-T $(1 \mathrm{~h})$. Incubation with FHR-3 (CEP-BSA: $10 \mu \mathrm{g} / \mathrm{ml}$, MDA-BSA: $35 \mu \mathrm{g} / \mathrm{ml}$, MAA-BSA: $0.35 \mu \mathrm{g} / \mathrm{ml}$ ), FH (CEP-BSA: 1 $\mu \mathrm{g} / \mathrm{ml}$, MDA-BSA: $10 \mu \mathrm{g} / \mathrm{ml}$, MAA-BSA: $0.1 \mu \mathrm{g} / \mathrm{ml}$ ), and with anti-FHR-3 antibody RETC-2 (CEP-BSA: 100 $\mu \mathrm{g} / \mathrm{ml}$, MDA-BSA: $350 \mu \mathrm{g} / \mathrm{ml}$, MAA-BSA: $35 \mu \mathrm{g} / \mathrm{ml})$ in PBS $(1 \mathrm{~h})$ was performed. For the standard curves antigen serial dilutions (FHR3 0.7-1500 nM, FH 0.2-6451.6 nM) were incubated (PBS, $1 \mathrm{~h}$ ). Binding was detected either with mouse anti-FH (R\&D Systems, \#AF4999, PBS, $1 \mathrm{~h}$ ) and anti-mouse IgG-Fcy-POD (Jackson ImmunoResearch, \#115-035-164, PBS, 30 min) or StrepMAB-HRP (IBA Lifesciences, Goettingen, Germany, \#2-1509-001, PBS, $30 \mathrm{~min}$ ) to detect the FHR-3-strep. The signal was developed with 3,3',5,5'Tetramethylbenzidine (TMB, Seramun Diagnostica, Heidesee, Germany, \#S-004-4), and absorption was determined at $450 \mathrm{~nm}$.

\subsection{Expression of recombinant FHR-3 and FHR-1}

FHR-3 with a Strep-tag II was expressed in HEK293 cells (American Type Culture Collection) as previously described (10).

FHR-1 was transiently expressed in HEK293 cells. For this, the CFHR1 gene was cloned into expression vector pEXPRIBA103 containing a c-terminal Strep-tag II (IBA) by using specific in-house-designed primer pairs (Metabion, Table S 1). The generated construct pEXPR-CFHR1 was transiently inserted into HEK293 cells (Thermo Fisher Scientific) with TransIT-LT1 Transfection Reagent (Mirus Bio, Madison, WI, USA, \#MIR2305), according to the manufacturer's protocol. FHR-1 with Strep-tag II was purified from HEK293 
supernatants using Strep-Tactin Sepharose columns (IBA). After gradient elution of FHR-1, the recombinant protein was concentrated by vacuum centrifugation. Protein purity was detected with Coomassie staining and Western blot using a specific anti-FHR-1 antibody (R\&D Systems, \#MAB4247).

\subsection{Protein Secretion Assays}

FHR-3 and properdin levels in cell culture supernatants were determined using sandwich ELISA, as described previously $(10,36)$. C3 and CFB secretion levels of ARPE-19 cells were determined using a MILLIPLEX MAP Human Complement Panel 1 and 2 (Merck, \#HCMP1MAG-19K, HCMP2MAG-19K). IL-1ß, IL-18, IL-6 and TNF- $a$ concentrations were determined according to the protocol of a custom ProcartaPlex ${ }^{\circledR}$ multiplex immunoassay kit (Thermo Fisher Scientific, \#PPX-05). The readout of the multiplex assays was performed using a Magpix instrument (Luminex, Austin, TX, USA). Vascular endothelial growth factor (VEGF)-a concentrations were determined using a human VEGF Quantikine ELISA Kit (R\&D systems).

\subsection{Western blot}

Proteins were dissolved in RIPA buffer (Sigma-Aldrich, \#R0278) with protease and phosphatase inhibitors (1:100, Sigma-Aldrich, \#P8340). Samples were diluted in reducing ROTI®Load 1 (Carl Roth, Karlsruhe, Germany, \#K929.1) and denatured $\left(95^{\circ} \mathrm{C}, 10 \mathrm{~min}\right)$. Following sample separation in a $12 \%$ SDS-PAGE, proteins were transferred onto an activated polyvinylidene difluoride membrane using a wet-blotting system. Membranes were blocked with 5\% BSA/TBS-T $(1 \mathrm{~h})$ and incubated with specific primary antibodies (5\% BSA/TBS-T, overnight): anti-C3b-a (Progen, Heidelberg, Germany, \#61019), anti-CFB (Merck, \#341272), anti-C3aR (Antibodies-online, \#ABIN682213), anti-CD11b (Biorbyt, \#orb19554), antiGAPDH. Detection was performed using peroxidase-conjugated anti-species antibodies (TBS, $1 \mathrm{~h}$ ): antimouse IgG-Fcy-POD (Jackson ImmunoResearch, \#115-035-164), anti-goat IgG-Fcy-POD (Jackson ImmunoResearch, \#305-035-003), anti-rabbit IgG-Fcy-POD (Jackson ImmunoResearch, \#111-035-003), anti-GAPDH-HRP (Cell Signaling Technology, \#3683). Visualization was performed by WesternSure PREMIUM Chemiluminescent Substrate (LI-COR, Bad Homburg, Germany) in a Fluor Chem FC2 Imaging System (Alpha Innotech, San Leandro, CA, USA). Afterwards, Western blots were quantified against a GAPDH housekeeping protein and calculated using Image Studio Lite (LI-COR).

\subsection{Chimerization of anti-FHR-3 antibody RETC-2}

Variable regions (heavy and light chain) of murine RETC-2 (anti-FHR-3) and murine control antibody (antiBSA) were determined as described previously (10) and cloned into plasmids containing either human IgG4 heavy chain (pFUSE-CHIg-hG4e1, Invivogen, Toulouse, France, \#pfuse-hchg4e1) or human IgG kappa light chain (pFUSE2-CLIg-hk, Invivogen, \#pfuse2-hclk), according to the manufacturer's protocol. The generated constructs for the heavy and light chains were transiently co-transfected into HEK293 cells (Thermo Fisher Scientific, using IgG-free FCS in Medium) using a ratio of $3: 2$ (light chain construct : heavy chain construct) with TransIT-LT1 Transfection Reagent (Mirus), according to the manufacturer's protocol. Cell supernatants were tested for antibody characterization and for specific FHR-3 binding using 
ELISA and Western blots. Chimerized antibodies were purified using Protein-A columns HiTrap ${ }^{\circledR}$ MabSelect ${ }^{\text {TM }}$ SuRe $^{\text {TM }}$ (Merck, \#GE11-0034-94) and named as follows: RETC-2-ximab, control-ximab.

\subsection{Statistics}

Statistics were performed using GraphPad Prism 8 (GraphPad Software Inc., San Diego, CA, USA). All data are expressed as mean \pm standard deviation (SD) unless stated otherwise. Detailed information about specific n-values, implemented statistical analyses and coding of significance levels are documented in each figure and figure legend, respectively.

\section{Results}

We previously reported that FHR-3 is co-localized with activated macrophages/microglia cells in an aged and inflamed retina, but not detectable in a healthy retina (10). Due to our additional results, showing that RPE cells in response to stress increased the expression of complement components and proinflammatory factors (30), we proposed that FHR-3 could be a stress factor for the RPE in the aged retina promoting retinal degeneration (10). Consequently, we investigated here the cell-specific complement and inflammation-associated response of RPE cells exposed to FHR-3.

To exclude a genotype-primed reactivity of ARPE-19 cells and human primary RPE cells (hpRPE), used in this study, we characterized the most common AMD-associated SNPs within genes of the complement pathway (37). Homogenous AMD-risk SNPs could not be detected in the examined RPE cells, instead heterozygous SNPs were present in the $\mathrm{CFH}$ and $\mathrm{C} 3$ gene of ARPE-19 and $\mathrm{CFH}, \mathrm{C2} / \mathrm{CFB}, \mathrm{CFI}$ and ARMS gene of hpRPE cells (Fig. S 1A).

We verified the epithelial phenotype of the used ARPE-19 cells, passaged for 38 times and cultivated under in vivo-like conditions, by staining tight junction protein zonula occludens 1 (ZO-1). A polarized monolayer could be detected for untreated and FHR3 treated cells, showing that FHR-3 had no effect on stable cell-cell contacts. We also excluded that ARPE-19 cell passaging had any influence on FHR-3 dependent tight junction formation by comparing ZO-1 stainings in passage number 38 (P38) with 25 (P25) (Fig. S 1D - G). Transepithelial resistance and cellular capacitance of the polarized ARPE19 cells were measured between $0.5-72 \mathrm{~h}$ of FHR-3-treatment. FHR-3 had no impact on cell barrier function and on cell membrane folding (Fig. S 1B). These characterizations resulted in a specific RPE phenotype, with a slight shift to mesenchymal characteristics established by mRNA expression analysis of EMT markers vimentin (VIM), a-smooth muscle actin (ACTA2) and collagen type 1 (COL 1A1) (Fig. S 1H - J). FHR-3 treatment increased VIM expression in ARPE-19 cells P38 and P25 compared to untreated controls (Fig. S 1H), whereas ACTA2 and COL1A1 were only raised in ARPE-19 cells P25 (Fig. S $11-\mathrm{J}$ ) indicating an early EMT caused by FHR-3 and already existing mesenchymal characteristics in high-passage ARPE-19 cells.

Due to the number of passages and the slight EMT, which is typical for aged human RPE cells (38), the investigated ARPE-19 cells P38 were termed senescent cells in this study. 


\section{FHR-3 was internalized by senescent ARPE-19 cells}

Previous reports described an interaction of proteins of the FH-protein family with damaged cells: FH was internalized by apoptotic ARPE-19 cells (21), FHR-1 and FHR5 bound to necrotic ARPE19 cells (23), and FHR-1 interacted with a necrotic-type endothelial cell line (20). In this study, we showed for the first time that FHR-3 was bound to and internalized by senescent viable ARPE-19 cells (Fig. 1, Fig. S 1C), knowing that CFHR3 mRNA is not expressed in these cells (Fig. S 3). Interaction of FHR-3 with ARPE-19 cells was confirmed by immunofluorescence resulting in FHR-3-positive ARPE-19 cells following FHR-3 incubation (Fig. 1A, B). Further, in the supernatant of the ARPE-19 cells supplemented with FHR-3 only $30 \%$ of the added FHR-3 remained in the apical and $5 \%$ in the basal supernatant compared to the added complement control protein properdin (FP), which was stable to $92 \%$ in the apical and $3 \%$ in the basal supernatant after incubation with ARPE-19 cells (Fig. S 1C). To investigate whether the complement regulator was internalized, we labelled FHR-3 with pH-sensitive dye pHrodo (FHR-3-pHrodo). This dye is non-fluorescent outside the cell, but fluoresces in acidic, cellular compartments like endosomes, phagosomes or lysosomes. Added FHR-3-pHrodo was detected inside senescent ARPE-19 cells indicating a phagocytosis or receptor-mediated endocytosis (Fig. 1D). This shift in fluorescence activity could not be detected when cells were incubated with FH-pHrodo.

Just recently, it was shown that FHR-3 binds to malondialdehyde (MDA)-epitopes (19). These OSE are present on the surface of stressed ARPE-19 cells (16). We wondered, if these neoepitopes could be ligands for FHR-3 internalization (Fig. 1). We determined specific binding of FHR-3 and FH either to OSE 2(wcarboxyethyl)pyrrole (CEP), MDA or malondialdehyde-acetaldehyde (MAA) (Fig. 2A, D, G). We detected a competitive binding of FHR-3 and FH to CEP, MDA and MAA. Interaction of FHR-3 and oxidative stress epitopes was not changed by additional incubation of FH (Fig. 2B, E, H), whereas a reduced FH interaction with CEP (38\%), MDA (47\%) and MAA (28\%) could be observed when FHR-3 was added as a competitor (Fig. 2C, F, I). Our previously published anti-FHR-3 antibody RETC2 (10) decreased binding of FHR-3 to CEP (29\%), MDA (44\%) and MAA (24\%) (Fig. 2B, E, H), and prevented the competitive effect of FHR-3 with $\mathrm{FH}$ for the interaction with CEP $(47 \%)$ and MDA (87\%). This impact could not be detected for MAA (Fig. 2C, F, I).

Here, we showed for the first time FHR-3 internalization by viable, senescent ARPE19 cells (Fig. 1), and determined peroxidation products CEP, MDA and MAA as potential ligands. FHR-3 bound to OSE and prevented their interaction with FH, which was reversed by anti-FHR-3 antibody RETC2 (10) (Fig. 2).

\section{FHR-3 increased endogenous complement activation}

Complement components are locally expressed by different retinal cell types and by ARPE- 19 cells (27, $30,31,39)$. Here, we showed that the complement regulator FHR3 enhanced complement expression and secretion of RPE cells (Fig. 3 - 5, Fig. S 2A). We demonstrated an increase of C3 mRNA expression in polarized senescent ARPE-19 cells and hpRPE cells after FHR-3 treatment, whereas no expression change was shown for FHR-1, FH or FP incubation (Fig. 3A, Fig. S 2A). On protein level, an increased C3 secretion after $24 \mathrm{~h}$ (Fig. 3B) and enhanced cell-associated C3 protein detection in cell lysates after $12 \mathrm{~h}$ FHR-3 
incubation compared to untreated cells were examined (Fig. 3C). We visualized accumulated intracellular C3, co-localized with Golgi complex, increased in 12 h FHR-3-treated ARPE-19 cells (Fig. 3D, E).

In line with our previous published data, where we reported C3 activation fragments in ARPE-19 cells under oxidative stress (30), we proved that FHR-3 induced C3 cleavage in ARPE-19 cells (Fig. 4). We detected raised levels of cell-associated C3b (101 kDa) after $12 \mathrm{~h}$ of FHR-3 treatment (Fig. 4A). However, C3c as a marker for inactivated C3 was time-dependently reduced $(5 \mathrm{~h}-24 \mathrm{~h})$ when ARPE-19 cells were incubated with FHR3 (Fig. 4B). Anaphylatoxin C3a was increased in FHR-3-treated cells and showed a translocation from the cytoplasm to the cell membrane after FHR-3 exposure (Fig. 4C).

Increased detection of CFB was also a consequence of FHR-3 addition to senescent ARPE-19 cells and hpRPE cells (Fig. 5, Fig. S 2B). CFB transcripts were highly elevated after $5 \mathrm{~h}$ and $24 \mathrm{~h}$ of FHR-3 incubation and no expression changes were shown for FHR-1, FH or FP treatment (Fig. 5A, Fig. S 2B). Enhanced CFB protein secretion after $24 \mathrm{~h}$ (Fig. 5B) and a time-dependent increase in cell-associated CFB protein expression in cell lysates from $5 \mathrm{~h}$ to $24 \mathrm{~h}$ of FHR-3 treatment were determined (Fig. 5C). CFB cleavage products $\mathrm{Bb}$ and $\mathrm{Ba}$ were also detected in ARPE-19 cells and raised in FHR-3-treated cells (Fig. S 1L). Using immunofluorescence, we showed accumulated intracellular CFB, partly co-localized with actin stress fibers in FHR-3 treated ARPE-19 cells (Fig. 5D, E).

Our data indicated a cell-associated complement-activating effect of FHR-3 by enhancing C3 and CFB expression as well as secretion and by anaphylatoxin C3a increase in immortal ARPE-19 cells (Fig. 3 - 5, Fig. S 4) as well as cultivated, post-mitotic, hpRPE cells (Fig. S 2A, B).

\section{FHR-3 altered complement receptor expression of ARPE-19 cells}

ARPE-19 cells express a variety of complement receptors $(30,40)$. It has recently been reported, that oxidatively stressed ARPE-19 cells increased expression of complement receptors CR3 and C5aR1 (30). Here, we showed that FHR-3 modified complement receptor C3aR (Fig. 6, Fig. S 2C) and CD11b (Fig. 7, Fig. S 2D) expression on senescent ARPE-19 cells and hPRPE cells, independently from any systemic complement.

C3AR mRNA expression was time-dependently changed with decreased transcripts after $5 \mathrm{~h}$ (Fig. 6, Fig. S 2C) and elevated expression after $24 \mathrm{~h}$ of FHR-3 exposure (Fig. 6A). This was partly in accordance with protein data showing decreased cell-associated C3aR levels in Western blots (Fig. 6B) and immunohistochemically (Fig. 6C) $5 \mathrm{~h}$ after FHR-3 incubation. An increase in C3aR protein expression $24 \mathrm{~h}$ after treatment, as shown at the mRNA level, could not be verified. This might be explained by storage of C3AR RNA into RNA granules, either stress granules or processing bodies (41).

ARPE-19 cells express the a-chain CD11b of the integrin complement receptor CR3 (30). We detected very low mRNA expression in untreated-, and no expression in FH-treated senescent ARPE-19 cells. When cells were incubated with FHR-3, CD11B expression increased significantly could be shown in ARPE-19 and hpRPE cells, respectively (Fig. 7A, Fig. S 2D). Western blot analyses revealed a time-dependent 
upregulation of CD11b from $5 \mathrm{~h}-24 \mathrm{~h}$ after FHR-3 incubation (Fig. 7B). Immunostainings of FHR-3 treated and untreated cells confirmed CD 11b accumulation after $5 \mathrm{~h}$ and $24 \mathrm{~h}$ (Fig. 7C). We did not observe a change in C5aR1 mRNA transcript levels following FHR-3 treatment, and C5aR2 mRNA transcripts were not detected in ARPE-19 cells (Fig. S 3).

These results revealed an FHR-3 triggered alteration of complement receptor C3aR and CD11b expression in immortal ARPE-19 cells (Fig. 6, 7, Fig. S 4) as well as cultivated, post-mitotic, primary RPE cells (Fig. $\mathbf{S}$ 2C, D).

\section{FHR-3 induced pro-inflammatory markers in ARPE-19 cells}

NLRP3 inflammasome activation is considered as an additional hallmark for the development of AMD (42). It has already been shown that anaphylatoxins C3a and C5a, and oxidative stress lead to the priming of NLRP3 and secretion of pro-inflammatory cytokines in ARPE-19 cells $(25,30,43)$. Here, we describe that FHR-3, a potential risk factor of AMD progression, induced inflammasome-associated proinflammation in ARPE-19 cells (Fig. 8A - D). NLRP3 mRNA expression was elevated $5 \mathrm{~h}$ and slightly decreased $24 \mathrm{~h}$ after FHR-3 incubation, whereas treatment with FHR-1, FH or FP did not show any expression changes (Fig. 8A). Accordingly, transcripts of $I L 1 B$ were also upregulated $5 \mathrm{~h}$ and $24 \mathrm{~h}$ after FHR-3 incubation (Fig. 8B). In line with this, determination of cytokine secretion levels of FHR-3-treated ARPE-19 cells revealed an upregulation of apical secretion of IL-1ß (Fig. 8C) and IL-18 (Fig. 8D) compared to untreated cells (Fig. 8C - D, dotted line).

Inflammatory cellular micro-environments are shaped by further key players, e.g. FOXP3, an inflammation-associated transcription factor, which triggers secretion of anti-inflammatory cytokines in regulatory T-cells. Expression of FOXP3 was detected recently in ARPE-19 cells $(30,44,45)$. We determined a time-dependent significant decrease in FOXP3 mRNA expression, after FHR-3 incubation (Fig. 8E), indicating a pro-inflammatory effect of FHR-3.

Additionally, the concentration of the pro-inflammatory cytokine IL- 6 was elevated in both, apical and basal supernatants of FHR-3 incubated senescent ARPE-19 cells (Fig. 8F). A tendency to higher secretion levels of tumor necrosis factor (TNF)-a could be detected in apical supernatants of ARPE-19 cells incubated with FHR-3 (Fig. 8G). However, a regulation of pro-angiogenic marker vascular endothelial growth factor (VEGF)-a could not be determined after FHR-3 incubation (Fig. 8H).

Toll-like receptors (TLR), abundantly expressed in the retina, especially TLR1 and TLR3 in RPE cells (46, 47), are pattern recognition molecules of the innate immune system. Previous studies have shown, that TLRs protect RPE cells from oxidative stress, and that a dysfunction of TLR is associated with the development of $\operatorname{AMD}(46,47)$. In this study, we described a complement-dependent regulation of TLR1 and TLR3 mRNA expression. Transcripts of TLR1 were significantly decreased in FHR-3-treated ARPE19 cells after 5 and $24 \mathrm{~h}$, whereas $T L R 3$ expression was time-dependently regulated with a respective decrease and increase after $5 \mathrm{~h}$ and $24 \mathrm{~h}$ of FHR-3 treatment compared to untreated ARPE-19 cells (Fig. 9A). 
Increased expression of inflammation-associated genes has also been associated with an impaired ubiquitin-proteasome signalling pathway in RPE cells, which negatively interferes with RPE metabolism $(48,49)$. Here we show proteasome subunits PSME1, PSMA7, PSMB5 and PSMB8 to be time-dependently altered when ARPE-19 cells were incubated with FHR-3. We detected a downregulation after $5 \mathrm{~h}$ and an upregulation after $24 \mathrm{~h}$ FHR-3 treatment of all tested proteasome subunit transcripts (Fig. 9B).

In sum, these results proposed a pro-inflammatory role of FHR-3 on aged RPE cells, independent from blood-derived complement components, which may have a so far unknown impact on AMD progression (Fig. S 4).

\section{RETC-2-ximab diminished the inflammatory effect of FHR-3}

In our previous studies we generated a highly specific monoclonal mouse antibody (mAb) against human FHR-3, RETC-2. We showed that RETC-2 inhibits binding of FHR-3 to C3b and regained interaction of FH to C3b (10). Similar results could be observed regarding FHR-3 and FH binding to OSES (CEP, MDA, MAA), as described afore (Fig. 2). To further investigate a therapeutic potential of RETC-2, chimerization was performed to replace complement-activating mouse regions of the mAb. The chimerized anti-FHR-3 mAb, called RETC-2-ximab, was tested in in vitro studies with polarized senescent ARPE-19 cells, which were treated apically for $24 \mathrm{~h}$ with FHR-3, FHR-3 and RETC-2-ximab or with FHR-3 and an antibody isotype control (control-ximab) (Fig. 10). Gene expression of C3 decreased significantly by $27 \%$ (Fig. 10A), CFB was reduced significantly by $48 \%$ (Fig. 10B), respectively, and C3AR mRNA expression was decreased by 21\% (Fig. 10C) after combined treatment with FHR3/RETC-2-ximab compared to FHR-3 alone or with the unspecific control-ximab in aged ARPE19 cells.

These promising results could offer a potential recovery of local complement homeostasis and a reduced progression of retinal degeneration using RETC-2-ximab in the future.

\section{Discussion}

It has been known for 15 years, that the deletion of the genes for CFHR3 and CFHR $1(\triangle C F H R 3 / 1)$ is associated with a protective effect for the development of $\operatorname{AMD}(7,50)$. However, the local biological function of FHR-3 and FHR-1 proteins is still poorly understood. We discovered recently, that FHR-3 - not expressed in RPE cells - is produced by macrophages/microglia within an aged, inflamed retina (10). In this study, we focussed on the intraocular role of FHR-3 on RPE cells and did not consider whether FHR-3 could interact basally with the RPE to examine a systemic effect, as Cipriani et al. recently described for FHR-4 (51).

Here, we demonstrated FHR-3 - but not FHR-1, FH or properdin - as a complement activating and proinflammatory protein on human RPE cells. Our in vitro studies, using senescent ARPE-19 cells and human primary RPE (hpRPE) cells, unveiled for the first time a putative local, intraocular function of FHR-3. In addition, we chimerized our highly specific monoclonal antibody against FHR-3 (10) - RETC-2-ximab - 
and showed promising inhibitory potential to represent a putative new therapeutic approach for FHR-3dependent autoimmune diseases.

\section{Endocytosis of FHR-3 by viable ARPE-19 cells}

Our data revealed an incorporation of FHR-3 by senescent viable RPE cells. So far, internalization of other FH-family proteins has been solely described for apoptotic cells. Martin et al. examined a specific FH uptake by apoptotic rendered Jurkat T- and ARPE-19 cells, whereas neither binding nor uptake could be confirmed by living cells (21). FHR1 and FHR-5 have also been reported to bind to necrotic RPE and endothelial cells, but an uptake was not described $(20,23)$.

FHR-3 intake could be linked to OSE on senescent RPE cells as potential ligands for FHR-3-dependent membrane invagination. Joseph et al. showed that oxidatively stressed RPE cells express lipid peroxidation product MDA on their cell surface (16). In accordance to Alic et al. we showed a specific binding of FHR-3 to MDA-epitopes and a competitive interaction with FH to these OSE (19). We also observed the same interaction of FHR-3 with CEP, a peroxidation product serving as biomarker for AMD (52). It is known that FH binds to OSE and thereby inhibits pro-inflammation in the aging eye $(17,18)$, indicating that FHR-3-FH-OSE interaction may impact the risk for AMD progression. Just recently, Irmscher et al. detected a binding of FHR-1 to MDA-epitopes (20) and Rudnick et al. showed an interaction of FHR-5 with lipid peroxidation products (53), both indicated an enhanced complement activity and inflammation in endothelial cells and monocytes. To what extend lipid peroxidation may be sufficient for cell membrane invagination and consequent uptake of FHR-3 in RPE cells - even this pathway of lipid-mediated endocytosis is poorly understood (54) - needs to be further investigated.

\section{FHR-3, a danger associated molecule within the eye?}

Beyond the classical function of the complement system as part of the humoral immune system, which has been known for more than 100 years, more and more non-canonical functions and the complosome have been assigned in the last decade, including the influence on cell metabolism, cell development and regeneration $(22,55,56)$. In the past years, rising data indicate that FHR proteins have complement activating properties $(20,21,23,24,51,53)$. While FHR-1, FHR-3, FHR-4 and FHR-5 compete systemically with $\mathrm{FH}$ for $\mathrm{C} 3 \mathrm{~b}$ binding, less is known about their non-canonical functions as cellular modulators $(23,51$, $57,58)$. Here, we treated serum-free, in vivo-like cultivated ARPE19 and hpRPE cells apically with FHR-3 to investigate the cell-associated complement and inflammatory response independent of any external complement sources.

We showed that FHR-3 is an inflammatory stimulator and may serve as a damage-associated sensing molecule for RPE cells (59). Just recently, we identified RPE cells as one of the major sources of complement expression in the mouse retina (39), hpRPE cells $(27,31)$ and in ARPE-19 cells (30). Here, we reported that FHR3 induced complement activation in cultured RPE cells. C3 cleavage was indicated by increased C3b protein detection and accumulation of C3a in ARPE-19 cells specifically following FHR-3 treatment, but not with FHR-1, FH or properdin incubation. Contrary, Martin et al. showed that apoptotic 
ARPE-19 cells - not cultivated under in vivo-like conditions - internalized FH leading to increased cleavage and deposition of endogenous C3 (21). Previous studies investigating oxidative stress in ARPE19 cells also reported increased C3 accumulation and secretion of C3 and C3a $(30,60)$.

We also reported a time-dependent redistribution of C3a to the cell membrane in FHR3 treated ARPE-19 cells. C3a, especially via C3aR signaling, is known to disrupt RPE function and promote AMD progression (61). In a previous study, C3a overexpression leaded to formation of sub-RPE deposits which are associated with early-stage AMD (49). Local C3a effects could be also reported in other cells: Liszewski et al. described that intracellular lysosomal $\mathrm{C} 3 \mathrm{a}$ led to the activation of the $\mathrm{C} 3 \mathrm{a}$ receptor (C3aR), which was essential for the survival of T cells (62). In endothelial cells, C3a overexpression disrupted barrier integrity via C3aR-signaling (63).

Our data revealed for the first time FHR-3 as a novel cellular stressor for RPE cells, which could balance the physiological and inflammatory state of the outer retinal-blood barrier.

Asgari et al. described that C3a-mediated C3aR signaling in monocytes caused initiation of the NLRP3 inflammasome and secretion of the pro-inflammatory cytokine IL-1ß (64). Further, the C3 fragment receptor CR3, has been also associated with NLRP3 inflammasome activation in human primary RPE cells (65). Besides recently shown for ARPE-19 (30) and hpRPE cells (27), CR3 expression has been mainly associated with macrophages (66) so far.

Here, we showed that FHR-3 regulated time-dependently C3aR and CR3 expression in RPE cells. Longterm FHR-3 incubation increased complement receptor C3AR and $C D 11 b$ transcript levels in ARPE19 cells.

FHR-3 does not only possess complement-activating properties, but also triggers pro-inflammatory potentials in RPE cells. Supplementation of ARPE-19 cells with FHR-3 increased the mRNA expression of $N L R P 3$ and $I L 1 B$ and, subsequently, enhanced the secretion of pro-inflammatory cytokines IL- $1 B$ and IL18. Irmscher et al. described an FHR-1 triggered induction of NLRP3 inflammasome in monocytes (20). Inflammasome priming in RPE cells was shown to be influenced by addition of extracellular anaphylatoxins and oxidative stress so far (25). We added FHR-3 to the NLRP3 priming list. However, we demonstrated lately that exogenous added properdin, the main positive regulator of the complement system, reversed this effect and showed anti-inflammatory properties (27).

In line with these results, we also determined that FHR-3 increased secretion of the pro-inflammatory cytokine IL- 6 by ARPE- 19 cells. IL- 6 plays an important role during intraocular inflammation. Previous studies demonstrated an increased IL- 6 release by oxidatively stressed (67) and C3a-stimulated RPE cells (68).

FOXP3, an inflammation-associated transcription factor, promotes the secretion of anti-inflammatory cytokines in regulatory T cells (44). Busch et al. demonstrated that FOXP3 is expressed in ARPE-19 cells and activated by addition of anaphylatoxins $\mathrm{C} 3 \mathrm{a}$ and $\mathrm{C} 5 \mathrm{a}$ (45). Recent studies determined increased FOXP3 mRNA expression in oxidatively stressed ARPE-19 cells (30). In the present study, FOXP3 mRNA 
was decreased in FHR-3 stimulated ARPE-19 cells, which may be consistent with the pro-inflammatory effect of FHR-3 on RPE cells. However, the exact role of FOXP3 in RPE cells is not known so far.

Another risk factor for developing AMD, besides complement activation and increased inflammation, is a dysfunction of certain TLRs $(46,47)$. In RPE cells, mainly TLR1 and TLR3 are expressed (69). Here, we confirmed the mRNA expression of TLR1 and TLR3 in senescent ARPE-19 cells. FHR-3 inhibited TLR expression at an early time point. A relation between complement regulators and TLR signaling has not been described so far. Patel et al. demonstrated that TLR3 activation of stressed RPE cells protected cells from cell death, whereas TLR3 activation in unstressed RPE cells led to reduced cell viability (47). An interaction of TLRs with complement receptors has been described for B cells (70), but not yet for RPE cells.

The ubiquitin-proteasome signaling pathway is the major proteolytic pathway within cells. Upon aging and disease, damaged proteins accumulates in the retina, which implicates a tight regulation of this pathway (71). The proteasome in RPE cells is more susceptible to cellular stressors, than the ubiquitin conjugates. Therefore, a proper regulation of the proteasomes is important for the maintenance of RPE cell metabolism $(71,72)$. In this work, we showed for the first time that FHR-3 inhibited proteasome RNA expression in ARPE-19 cells. In line with this, anaphylatoxin C3a is known to inhibit proteasome activity in RPE cells which resulted in formation of sub-RPE deposits, a known symptom in early-stage AMD (49, 73). Additionally, Liu et al. demonstrated that oxidative stress also reduced proteasome activity in RPE cells (48). Downregulation of ubiquitin-proteasome subunits, mediated by complement activation, can also trigger formation of sub-RPE deposits, a known symptom in early-stage AMD $(49,73)$.

Related to these pro-inflammatory events triggered by FHR-3, we chimerized our anti-FHR-3 antibody RETC-2 and hypothesized that RETC-2-ximab might serve as a new therapeutic approach for treatment of degenerated eye diseases such as AMD. We demonstrated that RETC-2-ximab mitigated the effect of FHR-3 on senescent ARPE19 cells. These promising data needs to be further investigated to elucidate the potential of RETC-2-ximab restoring local complement homeostasis. Just recently, it has been shown that a local complement suppression can be an effective tool for treating geographic atrophy, a late-stage AMD. In a phase 2 trial, intravitreal injection of the C3 inhibitor Pegcetacoplan significantly reduced the geographic atrophy rate over 12 months (74).

\section{Conclusions}

Here, we demonstrated FHR-3 - but not FHR-1, FH or properdin - as a complement promoting and proinflammatory protein on human RPE cells. Our in vitro studies, using senescent ARPE- 19 cells and hpRPE cells, unveiled for the first time a putative local, intraocular function of FHR-3. In addition, we chimerized our highly specific monoclonal antibody against FHR-3 (10) - RETC-2-ximab - and showed promising inhibitory potential to represent a putative new therapeutic approach for FHR-3-dependent autoimmune diseases. 


\section{Abbreviations}

ACTA2 a-smooth muscle actin

AMD age-related macular degeneration

ARPE-19 human adult retinal pigment epithelium cells

BSA bovine serum albumin

$\mathrm{C}_{\mathrm{Cl}}$ cellular capacitance

CD11b cluster of differentiation molecule 11B (CR3 subunit)

CEP $\omega$-carboxyethyl)pyrrole

COL1A1 collagen type I, alpha 1

CR3 complement receptor 3

EMT epithelial-mesenchymal transition

$\mathrm{FH}$ factor $\mathrm{H}$

FHL-1 factor-H like protein 1

FHR-1 - 5 factor H-related proteins 1-5

FOXP3 forkhead box P3

FP properdin

hpRPE primary human RPE cells

MAA malondialdehyde-acetaldehyde

MDA malondialdehyde

NLRP3 NLR family pyrin domain containing 3

OSE oxidation-specific epitopes

PSMA7 proteasome subunit alpha type-7

PSMB5 proteasome subunit beta type-5

PSMB8 proteasome subunit beta type-8 
PSME1 proteasome activator complex subunit 1

RETC-2 REgensburg Therapy Complement 2 (anti-FHR-3 antibody)

RETC-2-ximab chimerized REgensburg Therapy Complement 2 (anti-FHR-3 antibody)

RPE retinal pigment epithelium

SNP single nucleotide polymorphisms

TER Transepithelial Resistance

TLR toll-like receptors

TNF tumor necrosis factor

VIM vimentin

ZO-1 zonula occludens 1

\section{Declarations}

\section{Ethics approval and consent to participate}

The research complies with the human research act (HRA) stating that small quantities of bodily substances removed in the course of transplantation may be anonymized for research purposes without consent (HRA chapter 5, paragraph 38, Switzerland).

\section{Availability of data and materials}

All data generated or analyzed during this study are included in the published article or supplementary files.

\section{Consent for publication}

Not applicable.

\section{Acknowledgements}

We thank Renate Foeckler, Elfriede Eckert, Andrea Dannullis and Stephanie Lötscher for excellent technical support.

\section{Funding}

This project was supported by the Bright Focus Foundation (Grant Reference ID: M2015186 to DP), Dr. Werner Jackstädt-Stiftung (DP) and by the Maloch Stiftung (NS). 


\section{AUTHOR CONTRIBUTIONS}

Conceptualization: N.S. and D.P.; Data curation: N.S. and D.P.; Formal analysis: N.S.; Funding acquisition: N.S. and D.P.; Investigation: N.S., A.R., D.M.C., A.S., V.E. and D.P.; Methodology: N.S., A.R., A.S., V.E. and D.P.; Project administration: N.S. and D.P.; Supervision: H.J. and D.P.; Visualization: N.S. and D.P.; Writing original draft: N.S.; Writing - review and editing: N.S., A.S., V.E. and D.P. All authors have read and agreed to the published version of the manuscript.

\section{Conflict of interest}

The authors declare no competing financial interests.

\section{References}

1. Sjoberg AP, Trouw LA, Blom AM. Complement activation and inhibition: a delicate balance. Trends Immunol. 2009;30:83-90.

2. Medjeral-Thomas N, Pickering MC. The complement factor H-related proteins. Immunological Reviews. 2016;274:191-201.

3. Sánchez-Corral P, Pouw RB, López-Trascasa M, Józsi M. Self-Damage Caused by Dysregulation of the Complement Alternative Pathway: Relevance of the Factor H Protein Family. Frontiers in Immunology. 2018;9:1607-.

4. Cserhalmi M, Papp A, Brandus B, Uzonyi B, Józsi M. Regulation of regulators: Role of the complement factor H-related proteins. Seminars in Immunology. 2019;45:101341-.

5. Klein RJ, Zeiss C, Chew EY, Tsai J-Y, Sackler RS, Haynes C, et al. Complement Factor H Polymorphism in Age-Related Macular Degeneration. Science. 2005;308:385-9.

6. Hageman GS, Anderson DH, Johnson LV, Hancox LS, Taiber AJ, Hardisty LI, et al. A common haplotype in the complement regulatory gene factor $\mathrm{H}(\mathrm{HF} 1 / \mathrm{CFH})$ predisposes individuals to agerelated macular degeneration. Proceedings of the National Academy of Sciences of the United States of America. 2005;102:7227-32.

7. Spencer KL, Hauser Ma, Olson LM, Schmidt S, Scott WK, Gallins P, et al. Deletion of CFHR3 and CFHR1 genes in age-related macular degeneration. Human Molecular Genetics. 2008;17:971-7.

8. Zouache MA, Bennion A, Hageman JL, Pappas C, Richards BT, Hageman GS. Macular retinal thickness differs markedly in age-related macular degeneration driven by risk polymorphisms on chromosomes 1 and 10. Sci Rep. 2020;10:21093.

9. Clark SJ, Schmidt CQ, White AM, Hakobyan S, Morgan BP, Bishop PN. Identification of factor H-like protein 1 as the predominant complement regulator in Bruch's membrane: implications for agerelated macular degeneration. Journal of immunology (Baltimore, Md : 1950). 2014;193:4962-70.

10. Schäfer N, Grosche A, Reinders J, Hauck SM, Pouw RB, Kuijpers TW, et al. Complement Regulator FHR-3 Is Elevated either Locally or Systemically in a Selection of Autoimmune Diseases. Frontiers in Immunology. 2016;7:1-16. 
11. Strauss O. The retinal pigment epithelium in visual function. Physiological Reviews. 2005;85:845-81.

12. Lakkaraju A, Umapathy A, Tan LX, Daniele L, Philp NJ, Boesze-Battaglia K, et al. The cell biology of the retinal pigment epithelium. Progress in Retinal and Eye Research. 2020:100846-.

13. Lopez-Otin C, Blasco MA, Partridge L, Serrano M, Kroemer G. The hallmarks of aging. Cell. 2013;153:1194-217.

14. Kaarniranta K, Kajdanek J, Morawiec J, Pawlowska E, Blasiak J. PGC-1alpha Protects RPE Cells of the Aging Retina against Oxidative Stress-Induced Degeneration through the Regulation of Senescence and Mitochondrial Quality Control. The Significance for AMD Pathogenesis. Int J Mol Sci. 2018;19:2317.

15. Schutt F, Bergmann M, Holz FG, Kopitz J. Proteins Modified by Malondialdehyde, 4-Hydroxynonenal, or Advanced Glycation End Products in Lipofuscin of Human Retinal Pigment Epithelium. Investigative Opthalmology \& Visual Science. 2003;44:3663-.

16. Joseph K, Kulik L, Coughlin B, Kunchithapautham K, Bandyopadhyay M, Thiel S, et al. Oxidative stress sensitizes retinal pigmented epithelial (RPE) cells to complement-mediated injury in a natural antibody-, lectin pathway-, and phospholipid epitope-dependent manner. The Journal of Biological Chemistry. 2013;288:12753-65.

17. Weismann D, Hartvigsen K, Lauer N, Bennett KL, Scholl HP, Charbel Issa P, et al. Complement factor H binds malondialdehyde epitopes and protects from oxidative stress. Nature. 2011;478:76-81.

18. Borras C, Canonica J, Jorieux S, Abache T, El Sanharawi M, Klein C, et al. CFH exerts anti-oxidant effects on retinal pigment epithelial cells independently from protecting against membrane attack complex. Scientific Reports. 2019;9:13873-.

19. Alic L, Papac-Milicevic N, Czamara D, Rudnick RB, Ozsvar-Kozma M, Hartmann A, et al. A genomewide association study identifies key modulators of complement factor $\mathrm{H}$ binding to malondialdehyde-epitopes. PNAS. 2020;117:9942-51.

20. Irmscher S, Brix SR, Zipfel SLH, Halder LD, Mutlutürk S, Wulf S, et al. Serum FHR1 binding to necrotictype cells activates monocytic inflammasome and marks necrotic sites in vasculopathies. Nature Communications. 2019;10:2961-.

21. Martin M, Leffler J, Smoląg KI, Mytych J, Björk A, Chaves LD, et al. Factor H uptake regulates intracellular $\mathrm{C} 3$ activation during apoptosis and decreases the inflammatory potential of nucleosomes. Cell Death and Differentiation. 2016;23:903-11.

22. Arbore G, Kemper C, Kolev M. Intracellular complement - the complosome - in immune cell regulation. Molecular Immunology. 2017;89:2-9.

23. Kárpáti É, Papp A, Schneider AE, Hajnal D, Cserhalmi M, Csincsi Ál, et al. Interaction of the Factor H Family Proteins FHR-1 and FHR-5 With DNA and Dead Cells: Implications for the Regulation of Complement Activation and Opsonization. Frontiers in Immunology. 2020;11:1297-.

24. Csincsi Ál, Szabó Z, Bánlaki Z, Uzonyi B, Cserhalmi M, Kárpáti É, et al. FHR-1 Binds to C-Reactive Protein and Enhances Rather than Inhibits Complement Activation. Journal of Immunology. 2017;199:292-303. 
25. Brandstetter C, Holz FG, Krohne TU. Complement Component C5a Primes Retinal Pigment Epithelial Cells for Inflammasome Activation by Lipofuscin-mediated Photooxidative Damage. The Journal of Biological Chemistry. 2015;290:31189-98.

26. Wang L, Cano M, Datta S, Wei H, Ebrahimi KB, Gorashi Y, et al. Pentraxin 3 recruits complement factor $\mathrm{H}$ to protect against oxidative stress-induced complement and inflammasome overactivation. The Journal of Pathology. 2016;240:495-506.

27. Schäfer N, Wolf HN, Enzbrenner A, Schikora J, Reichenthaler M, Enzmann V, et al. Properdin Modulates Complement Component Production in Stressed Human Primary Retinal Pigment Epithelium Cells. Antioxidants. 2020;9:793-.

28. Fernandez-Godino R, Bujakowska KM, Pierce EA. Changes in extracellular matrix cause RPE cells to make basal deposits and activate the alternative complement pathway. Human Molecular Genetics. 2018;27:147-59.

29. Sugita S, Makabe K, Fujii S, Takahashi M. Detection of complement activators in immune attack eyes after iPS-derived retinal pigment epithelial cell transplantation. Investigative Ophthalmology and Visual Science. 2018;59:4198-209.

30. Trakkides T-O, Schäfer N, Reichenthaler M, Kühn K, Brandwijk RJMGE, Toonen EJM, et al. Oxidative Stress Increases Endogenous Complement-Dependent Inflammatory and Angiogenic Responses in Retinal Pigment Epithelial Cells Independently of Exogenous Complement Sources. Antioxidants. 2019;8:548-

31. Pauly D, Agarwal D, Dana N, Schafer N, Biber J, Wunderlich KA, et al. Cell-Type-Specific Complement Expression in the Healthy and Diseased Retina. Cell Rep. 2019;29:2835-48.

32. Brandstetter C, Mohr LKM, Latz E, Holz FG, Krohne TU. Light induces NLRP3 inflammasome activation in retinal pigment epithelial cells via lipofuscin-mediated photooxidative damage. Journal of molecular medicine (Berlin, Germany). 2015;93(8):905-16.

33. Mohr LKM, Hoffmann AV, Brandstetter C, Holz FG, Krohne TU. Effects of Inflammasome Activation on Secretion of Inflammatory Cytokines and Vascular Endothelial Growth Factor by Retinal Pigment Epithelial Cells. Investigative Opthalmology \& Visual Science. 2015;56:6404-.

34. Blenkinsop TA, Salero E, Stern JH, Temple S. The Culture and Maintenance of Functional Retinal Pigment Epithelial Monolayers from Adult Human Eye. Methods in Molecular Biology. 2012;945:4565.

35. Lu L, Gu X, Hong L, Laird J, Jaffe K, Choi J, et al. Synthesis and structural characterization of carboxyethylpyrrole-modified proteins: mediators of age-related macular degeneration. Bioorganic \& Medicinal Chemistry. 2009;17:7548-61.

36. Pauly D, Nagel BM, Reinders J, Killian T, Wulf M, Ackermann S, et al. A Novel Antibody against Human Properdin Inhibits the Alternative Complement System and Specifically Detects Properdin from Blood Samples. PloS One. 2014;9:96371-.

37. Fritsche LG, Igl W, Bailey JNC, Grassmann F, Sengupta S, Bragg-Gresham JL, et al. A large genomewide association study of age-related macular degeneration highlights contributions of rare and 
common variants. Nature Genetics. 2016;48:134-43.

38. Zhou M, Geathers JS, Grillo SL, Weber SR, Wang W, Zhao Y, et al. Role of Epithelial-Mesenchymal Transition in Retinal Pigment Epithelium Dysfunction. Front Cell Dev Biol. 2020;8:501.

39. Schäfer N, Grosche A, Schmitt SI, Braunger BM, Pauly D. Complement Components Showed a TimeDependent Local Expression Pattern in Constant and Acute White Light-Induced Photoreceptor Damage. Frontiers in Molecular Neuroscience. 2017;10:197-.

40. Thurman JM, Renner B, Kunchithapautham K, Ferreira VP, Pangburn MK, Ablonczy Z, et al. Oxidative stress renders retinal pigment epithelial cells susceptible to complement-mediated injury. The Journal of Biological Chemistry. 2009;284:16939-47.

41. Hwang YE, Baek YM, Baek A, Kim D-E. Oxidative stress causes Alu RNA accumulation via PIWIL4 sequestration into stress granules. BMB Reports. 2019;52:196-201.

42. Gao J, Liu RT, Cao S, Cui JZ, Wang A, To E, et al. NLRP3 inflammasome: activation and regulation in age-related macular degeneration. Mediators of Inflammation. 2015;2015:690243-.

43. Brandstetter C, Patt J, Holz FG, Krohne TU. Inflammasome priming increases retinal pigment epithelial cell susceptibility to lipofuscin phototoxicity by changing the cell death mechanism from apoptosis to pyroptosis. Journal of Photochemistry and Photobiology B: Biology. 2016;161:177-83.

44. Le Friec G, Köhl J, Kemper C. A complement a day keeps the Fox(p3) away. Nature Immunology. 2013;14:110-2.

45. Busch C, Annamalai B, Abdusalamova K, Reichhart N, Huber C, Lin Y, et al. Anaphylatoxins activate Ca2+, Akt/PI3-Kinase, and FOX01/FoxP3 in the retinal pigment epithelium. Frontiers in Immunology. 2017;8:703.

46. Yang Z, Stratton C, Francis PJ, Kleinman ME, Tan PL, Gibbs D, et al. Toll-like Receptor 3 and Geographic Atrophy in Age-Related Macular Degeneration. New England Journal of Medicine. 2008;359:1456-63.

47. Patel AK, Hackam AS. Toll-like receptor 3 (TLR3) protects retinal pigmented epithelium (RPE) cells from oxidative stress through a STAT3-dependent mechanism. Molecular Immunology. 2013;54:12231.

48. Liu Z, Qin T, Zhou J, Taylor A, Sparrow JR, Shang F. Impairment of the ubiquitin-proteasome pathway in RPE alters the expression of inflammation related genes. Advances in Experimental Medicine and Biology. 2014;801:237-50.

49. Fernandez-Godino R, Pierce EA. C3a triggers formation of sub-retinal pigment epithelium deposits via the ubiquitin proteasome pathway. Scientific Reports. 2018;8:9679-.

50. Hageman GS, Hancox LS, Taiber AJ, Gehrs KM, Anderson DH, Johnson LV, et al. Extended haplotypes in the complement factor H ( CFH) and CFH-related ( CFHR ) family of genes protect against agerelated macular degeneration: Characterization, ethnic distribution and evolutionary implications. Annals of Medicine. 2006;38:592-604.

51. Cipriani V, Lorés-Motta L, He F, Fathalla D, Tilakaratna V, McHarg S, et al. Increased circulating levels of Factor H-Related Protein 4 are strongly associated with age-related macular degeneration. Nature 
Communications. 2020;11:778.

52. Gu X, Meer SG, Miyagi M, Rayborn ME, Hollyfield JG, Crabb JW, et al. Carboxyethylpyrrole Protein Adducts and Autoantibodies, Biomarkers for Age-related Macular Degeneration. Journal of Biological Chemistry. 2003;278:42027-35.

53. Rudnick RB, Chen Q, Stea ED, Hartmann A, Papac-Milicevic N, Person F, et al. FHR5 Binds to Laminins, Uses Separate C3b and Surface-Binding Sites, and Activates Complement on Malondialdehyde-Acetaldehyde Surfaces. The Journal of Immunology. 2018;200:2280-90.

54. Ewers H, Helenius A. Lipid-mediated endocytosis. Cold Spring Harbor Perspectives in Biology. 2011;3:1-14.

55. Mastellos DC, DeAngelis RA, Lambris JD. Complement-triggered pathways orchestrate regenerative responses throughout phylogenesis. Seminars in Immunology. 2013;25:29-38.

56. Kolev M, Dimeloe S, Le Friec G, Navarini A, Arbore G, Povoleri Giovanni A, et al. Complement Regulates Nutrient Influx and Metabolic Reprogramming during Th1 Cell Responses. Immunity. 2015;42:1033-47.

57. Goicoechea de Jorge E, Caesar JJE, Malik TH, Patel M, Colledge M, Johnson S, et al. Dimerization of complement factor $\mathrm{H}$-related proteins modulates complement activation in vivo. PNAS. 2013;110:4685-90.

58. Tortajada A, Uzonyi B, Jorge EGD. Factor H-related proteins determine complement-activating surfaces. Trends in Immunology 2015;36:374-84.

59. Schaefer L. Complexity of danger: The diverse nature of damage-associated molecular patterns. Journal of Biological Chemistry. 2014;289:35237-45.

60. Kunchithapautham K, Atkinson C, Rohrer B. Smoke exposure causes endoplasmic reticulum stress and lipid accumulation in retinal pigment epithelium through oxidative stress and complement activation. The Journal of Biological Chemistry. 2014;289:14534-46.

61. Rohrer B. Anaphylatoxin Signaling in Retinal Pigment and Choroidal Endothelial Cells: Characteristics and Relevance to Age-Related Macular Degeneration. Adv Exp Med Biol. 2018;1074:45-51.

62. Liszewski MK, Kolev M, Le Friec G, Leung M, Bertram Paula G, Fara Antonella F, et al. Intracellular Complement Activation Sustains T Cell Homeostasis and Mediates Effector Differentiation. Immunity. 2013;39:1143-57.

63. Propson NE, Roy ER, Litvinchuk A, Köhl J, Zheng H. Endothelial C3a receptor mediates vascular inflammation and BBB permeability during aging. Journal of Clinical Investigation. 2020;131:140966.

64. Asgari E, Friec GL, Yamamoto H, Perucha E, Sacks SS, Cook HT, et al. C3a modulates IL-1 b secretion in human monocytes by regulating ATP ef fl ux and subsequent NLRP3 in fl ammasome activation. Blood. 2013;122:3473-82.

65. Bian Z-M, Field MG, Elner SG, Kahlenberg JM, Elner VM. Distinct CD40L receptors mediate inflammasome activation and secretion of IL-1 $\beta$ and MCP-1 in cultured human retinal pigment 
epithelial cells. Experimental Eye Research. 2018;170:29-39.

66. Wagner C, Hänsch GM, Stegmaier S, Denefleh B, Hug F, Schoels M. The complement receptor 3, CR3 (CD11b/CD18), on T lymphocytes: activation-dependent up-regulation and regulatory function. European Journal of Immunology. 2001;31:1173-80.

67. Wu WC, Hu DN, Gao HX, Chen M, Wang D, Rosen R, et al. Subtoxic levels hydrogen peroxide-induced production of interleukin-6 by retinal pigment epithelial cells. Molecular Vision. 2010;16:1864-73.

68. Fernandez-Godino R, Garland DL, Pierce EA. A local complement response by RPE causes early-stage macular degeneration. Human Molecular Genetics. 2015;24:5555-69.

69. Kumar MV, Nagineni CN, Chin MS, Hooks JJ, Detrick B. Innate immunity in the retina: Toll-like receptor (TLR) signaling in human retinal pigment epithelial cells. Journal of Neuroimmunology. 2004;153:7-15.

70. Kremlitzka M, Mácsik-Valent B, Erdei A. Regulation of B cell functions by Toll-like receptors and complement. Immunology Letters. 2016;178:37-44.

71. Shang F, Taylor A. Roles for the ubiquitin-proteasome pathway in protein quality control and signaling in the retina: Implications in the pathogenesis of age-related macular degeneration. Molecular Aspects of Medicine. 2012;33:446-66.

72. Zhang X, Zhou J, Fernandes AF, Sparrow JR, Pereira P, Taylor A, et al. The Proteasome: A Target of Oxidative Damage in Cultured Human Retina Pigment Epithelial Cells. Investigative Opthalmology \& Visual Science. 2008;49:3622-

73. Ramos de Carvalho JE, Klaassen I, Vogels IMC, Schipper-Krom S, van Noorden CJF, Reits E, et al. Complement Factor C3a Alters Proteasome Function in Human RPE Cells and in an Animal Model of Age-Related RPE Degeneration. Investigative Opthalmology \& Visual Science. 2013;54:6489-

74. Liao DS, Grossi FV, El Mehdi D, Gerber MR, Brown DM, Heier JS, et al. Complement C3 Inhibitor Pegcetacoplan for Geographic Atrophy Secondary to Age-Related Macular Degeneration. Ophthalmology. 2020;127:186-95.

\section{Figures}



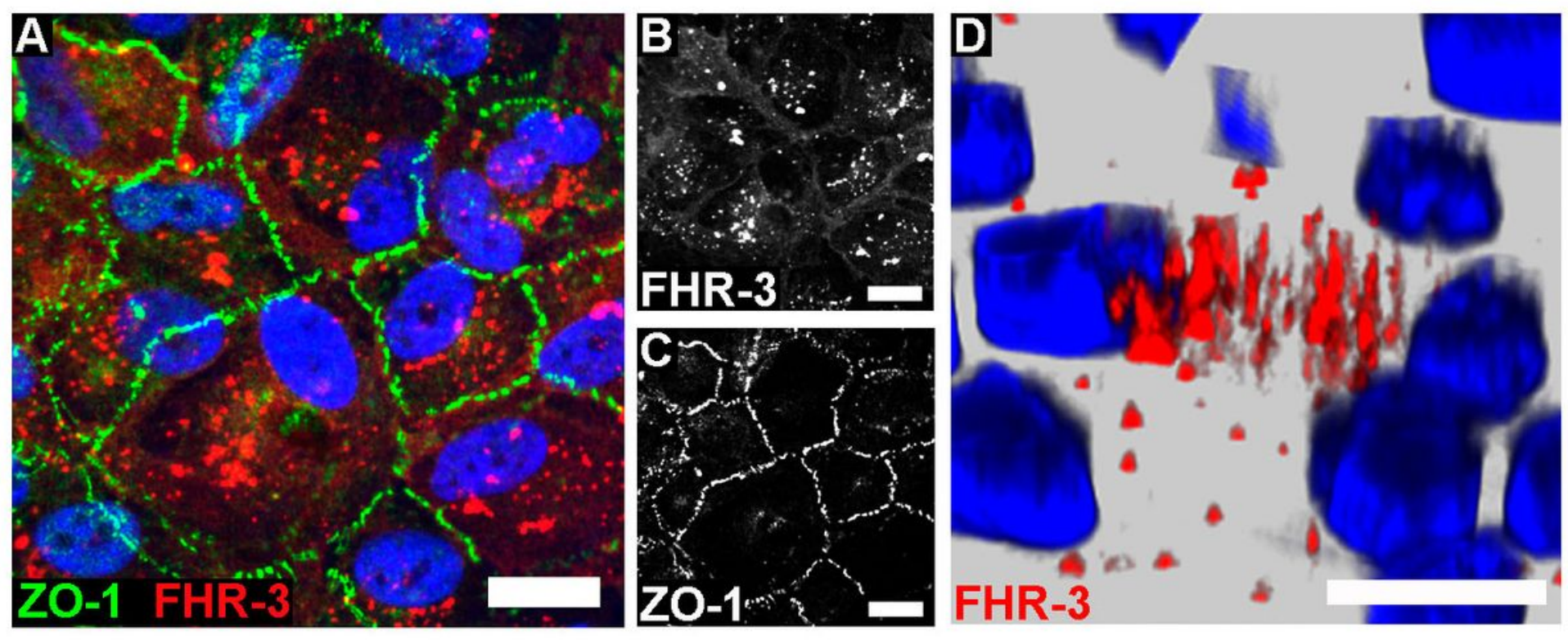

\section{Figure 1}

FHR-3 was internalized by ARPE-19 cells. Polarized, differentiated ARPE-19 cells were apically treated with FHR-3. (A) FHR-3 was specifically detected after $2 \mathrm{~h}$ incubation time by anti-FHR-3 antibody RETC-2 (red, B), cell-cell connections were labelled with anti-ZO-1 antibody (green, C). Magnification 200x. (D) FHR-3-pHrodo (red) was specifically detected inside senescent ARPE 19 cells. Magnification 400x. Scale bars $40 \mu \mathrm{m}$. Cell nuclei were stained with Hoechst. 
A

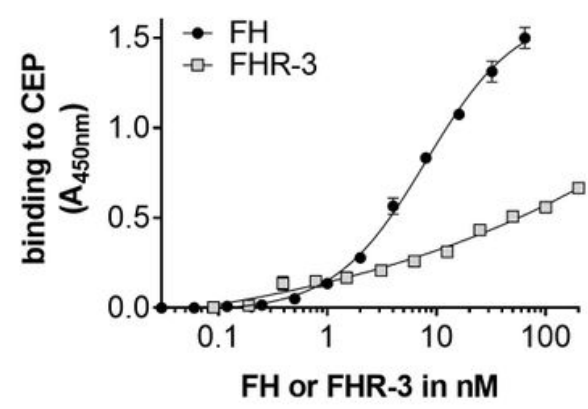

D
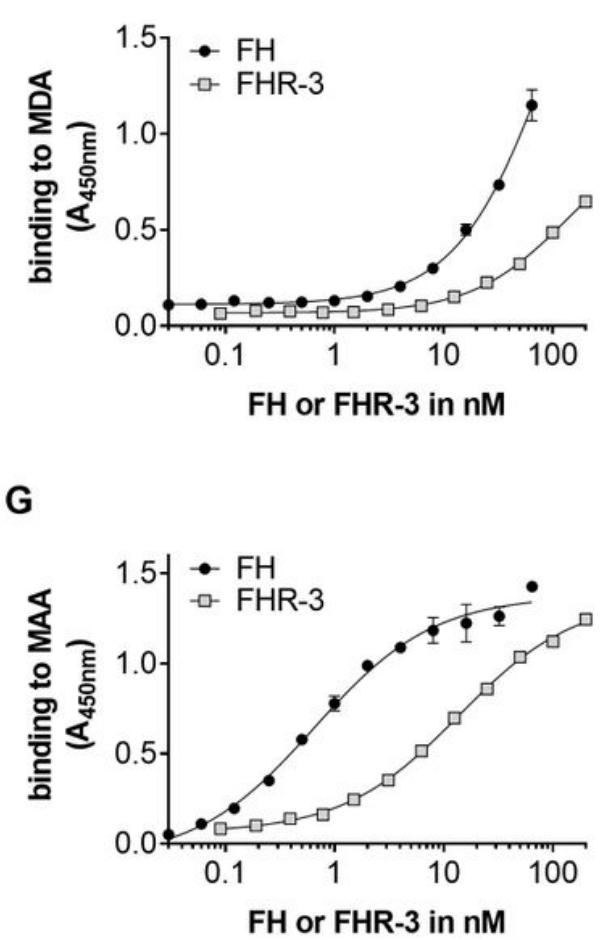

B

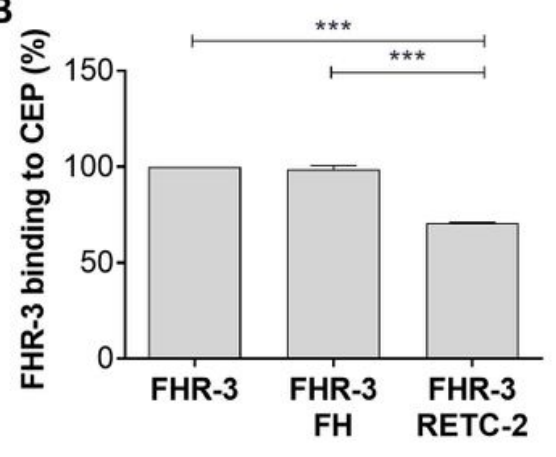

E
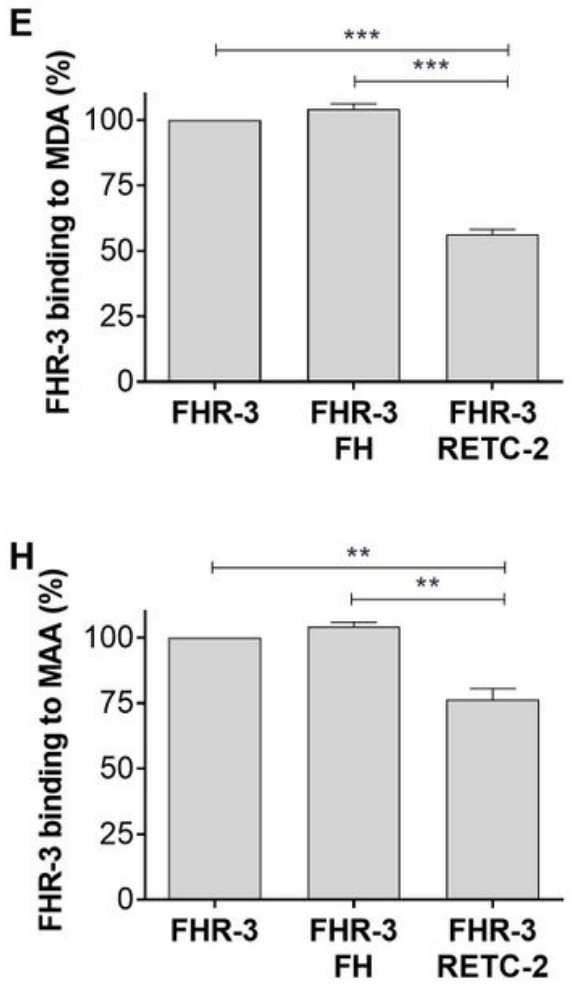

C

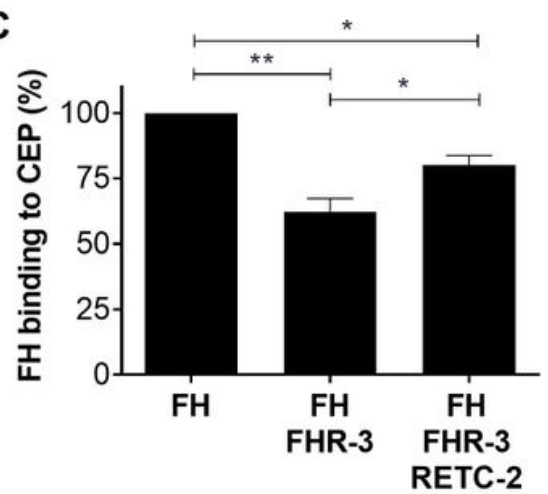

F
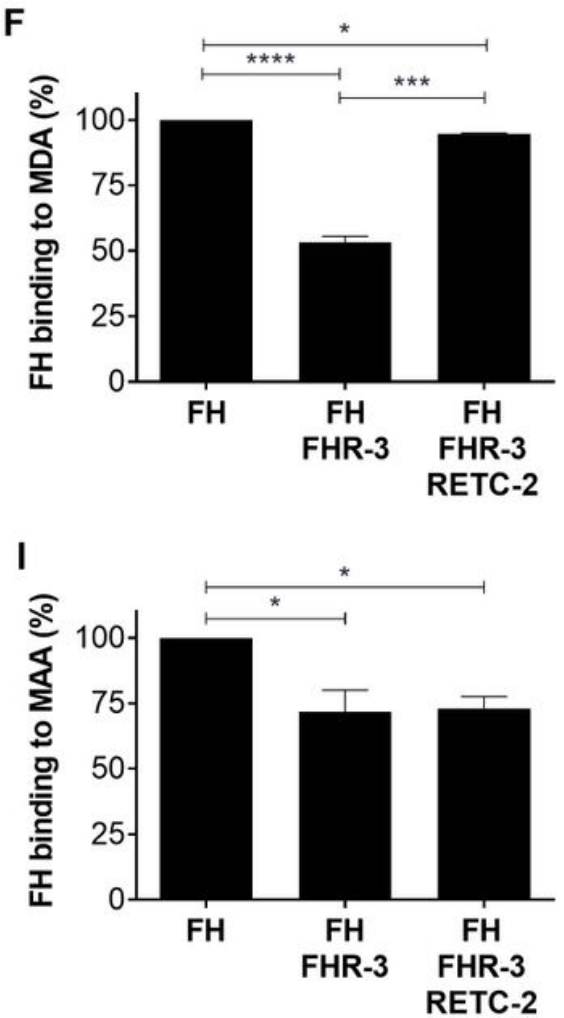

Figure 2

FHR-3 and FH interact with OSEs and RETC-2 reduced this competitive binding. All three lipid peroxidation products (A) CEP, (D) MDA, and (G) MAA interacted concentration dependently with FHR-3 and FH. FH (black) showed a higher binding strength than FHR-3 (grey) to the OSE. Interaction of FHR-3 with (B) CEP, (E) MDA, or (H) MAA could not be reduced by additional incubation with FH, but RETC-2 significantly reduced the binding of FHR-3 to all three peroxidation products. Interaction of $F H$ to $(C) C E P,(F)$ MDA, and (I) MAA was significantly reduced by additional incubation with FHR-3, and anti-FHR-3 antibody RETC-2 was able to reverse this inhibitory effect completely (F, MDA), partially (C, CEP), or not at all (I, MAA). ${ }^{\star *} \mathrm{p}<$ $0.01{ }^{*} \mathrm{p}<0.05$ (one-way ANOVA with Dunnett's multiple comparisons test, $\mathrm{n}=3$ ). 

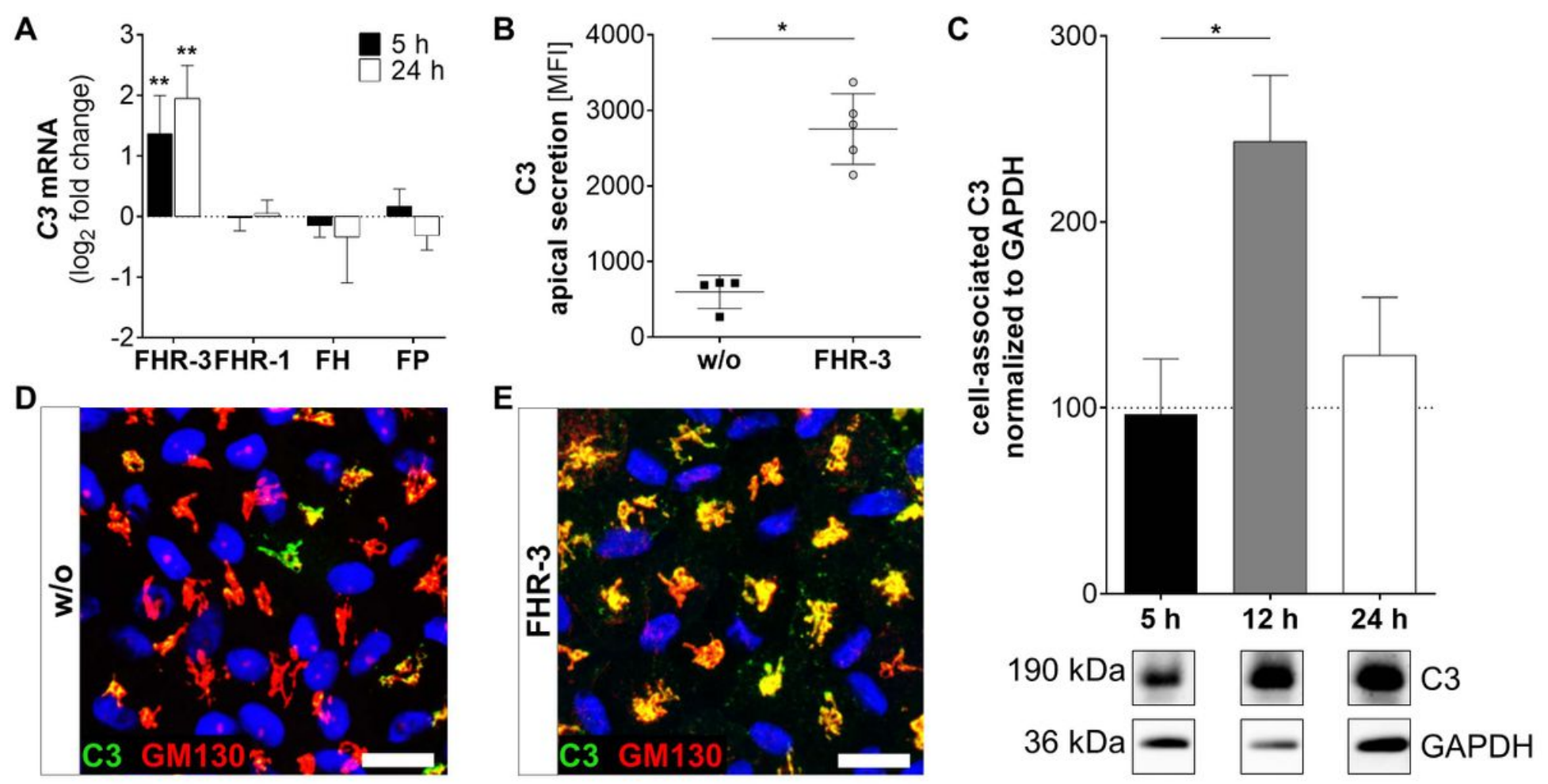

\section{Figure 3}

FHR-3 increased C3 expression and secretion in ARPE-19 cells. (A) C3 mRNA expression was increased 5 $\mathrm{h}$ and $24 \mathrm{~h}$ after apical treatment of ARPE-19 cells with FHR-3, but not after incubation with FHR-1, FH or $F P$, respectively. This effect could be confirmed at the protein level showing an FHR-3-dependent increase (B) in C3 protein secretion after $24 \mathrm{~h}$, (C) elevated C3 protein (190 kDa) in ARPE-19 cell lysates in Western blots after $12 \mathrm{~h}$, and $(D, E)$ increased intracellular $C 3$ protein levels by immunohistochemistry using antiC3 (green) and anti-GM130 (red, cis-Golgi marker) antibodies after $12 \mathrm{~h}$ treatment. C3 was co-localized with the cis-Golgi (yellow). Scale bars $40 \mu \mathrm{m}$. w/o untreated control (A, C dotted line). Mean with standard deviation is shown. Full Western blot in Fig. $S 1 \mathrm{~K} .{ }^{*} \mathrm{p} p<0.01,{ }^{*} \mathrm{p}<0.05$. (A, B) two-tailed, unpaired t-test, Mann-Whitney test $(A n=3, B n=2)$; (C) Kruskal-Wallis test, Dunn's multiple comparison test $(n=2)$.
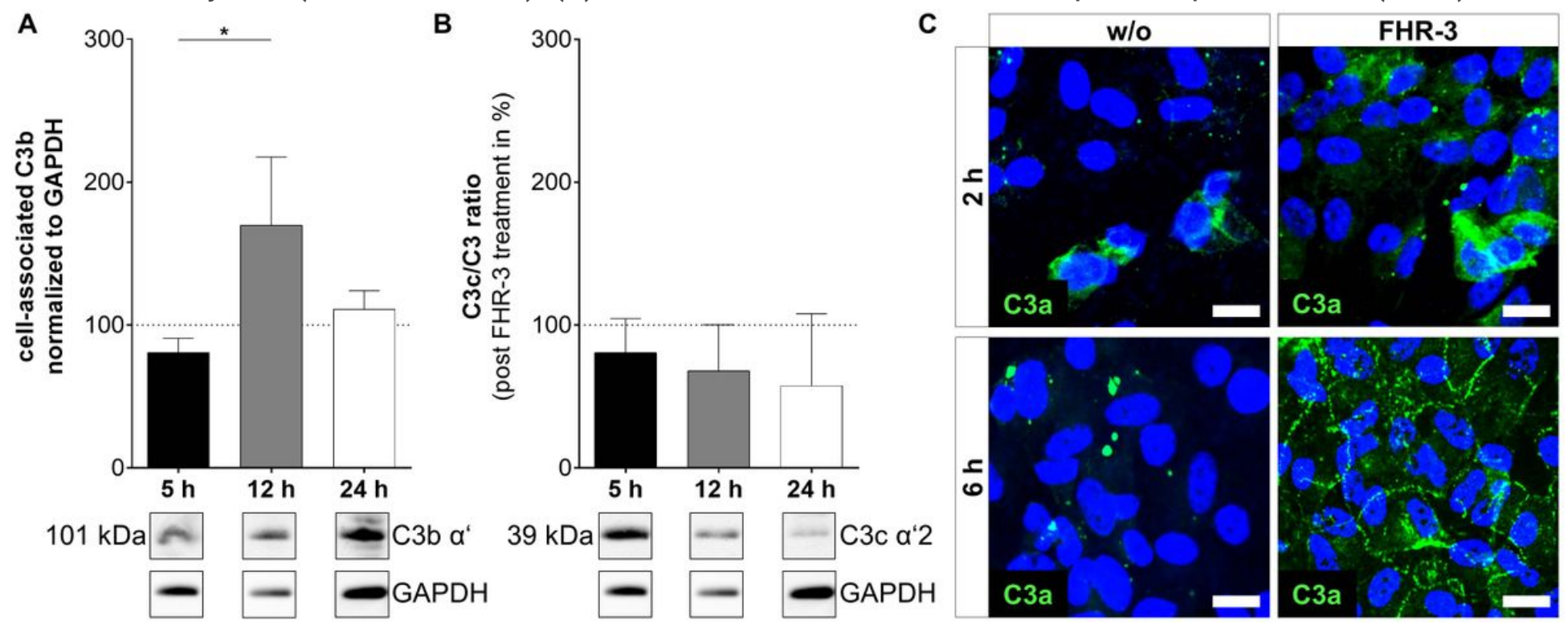


\section{Figure 4}

C3 cleavage products were changed in ARPE-19 cells after FHR-3 incubation. (A) Increased C3b levels (101 kDa) $12 \mathrm{~h}$ after FHR-3 treatment and (B) a time-dependent reduction of C3c fragments (39 kDa) in ratio to intact C3 were detected in Western blots of ARPE-19 cell lysates. Fig. S 1K shows full Western blots. (C) Anaphylatoxin C3a was detected by immunohistochemistry using a specific anti-C3a antibody (green). C3a increased time-dependently from $2 \mathrm{~h}$ to $6 \mathrm{~h}$ after FHR-3 treatment and was translocated from the cytoplasm (upper right panel) to the cell membrane (lower right panel). Scale bars $40 \mu \mathrm{m}$. w/o untreated control (dotted line). Mean with standard deviation is shown. ${ }^{\star} p<0.05$. (A, B) Kruskal-Wallis test, Dunn's multiple comparison test $(n=2)$.

A

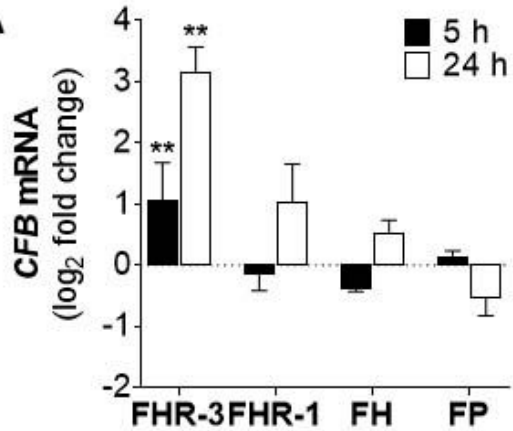

D

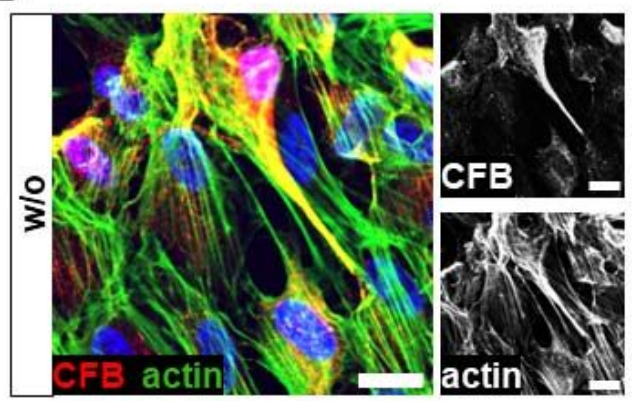

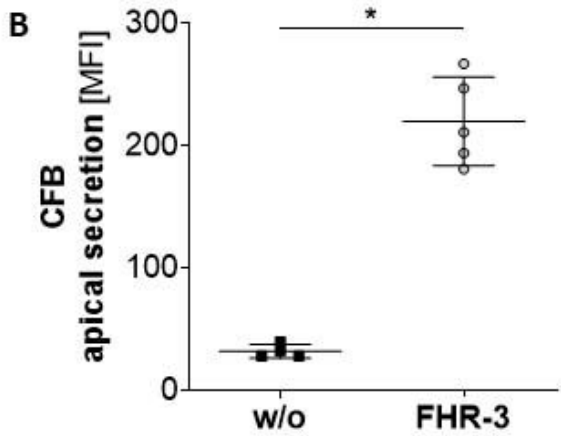

E

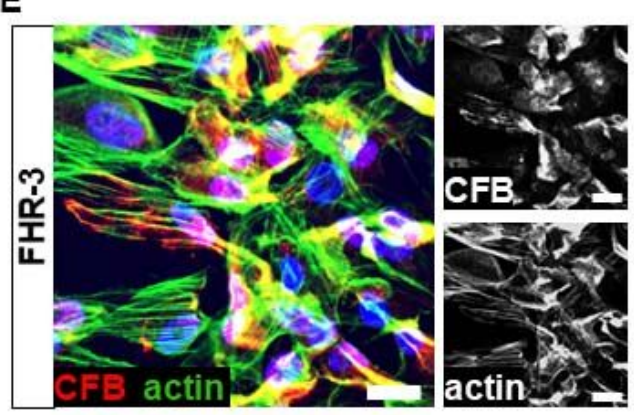

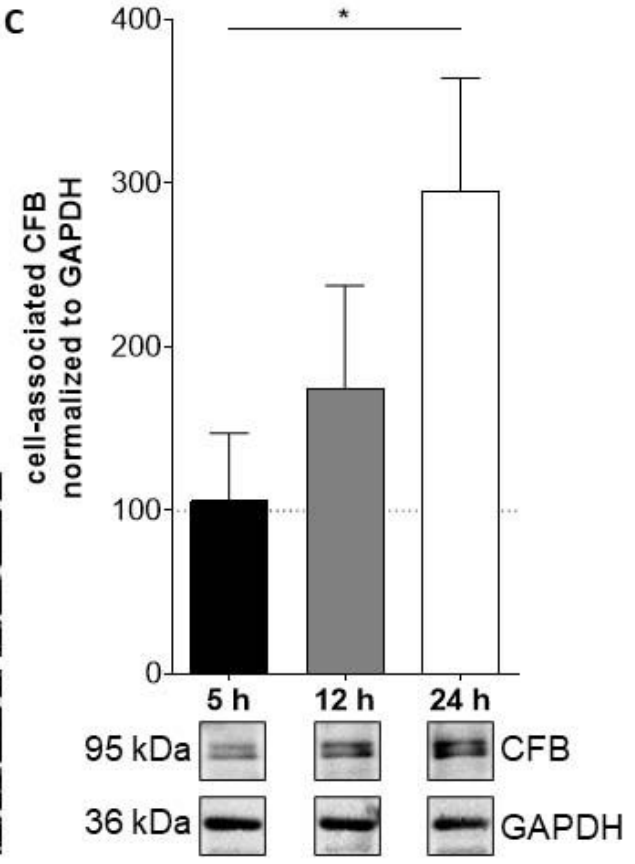

Figure 5

FHR-3 increased CFB expression and secretion in ARPE-19 cells. (A) CFB mRNA increased after apical FHR-3 treatment of ARPE-19 cells, but not following incubation with FHR-1, FH or FP. This effect could be confirmed at the protein level: (B) Apical CFB secretion was increased $24 \mathrm{~h}$ after FHR-3 incubation. (C) Western blots of ARPE-19 cell lysates detected a time-dependent increase in CFB levels (95 kDa) $24 \mathrm{~h}$ after FHR-3 treatment. (D, E) Increased CFB protein levels were detected by immunohistochemistry using specific anti-CFB (red) and anti-actin (green) antibodies $12 \mathrm{~h}$ after FHR-3 treatment. CFB was co-localized partly with actin stress fibers (yellow). Scale bars $40 \mu \mathrm{m}$. (A - C) w/o untreated control (dotted line). (A C) Mean with standard deviation is shown. ${ }^{* \star} p<0.01$, ${ }^{\star} p<0.05$. (A, B) two-tailed, unpaired t-test, MannWhitney test $(A n=3, B n=2)$; (C) Kruskal-Wallis test, Dunn's multiple comparison test $(n=2)$. 


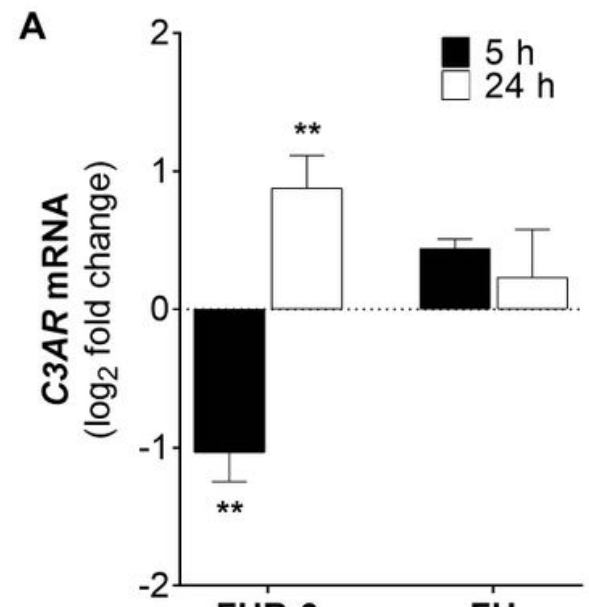

FHR-3
FH

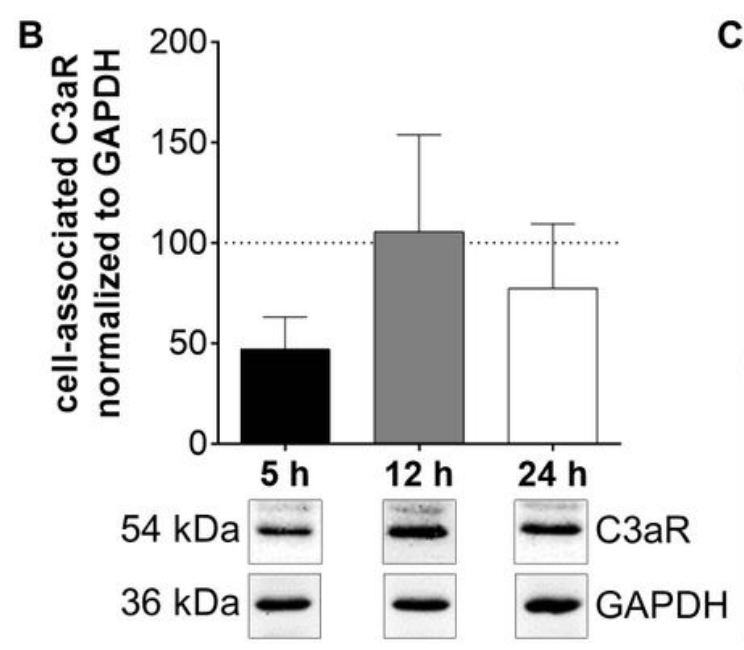

C

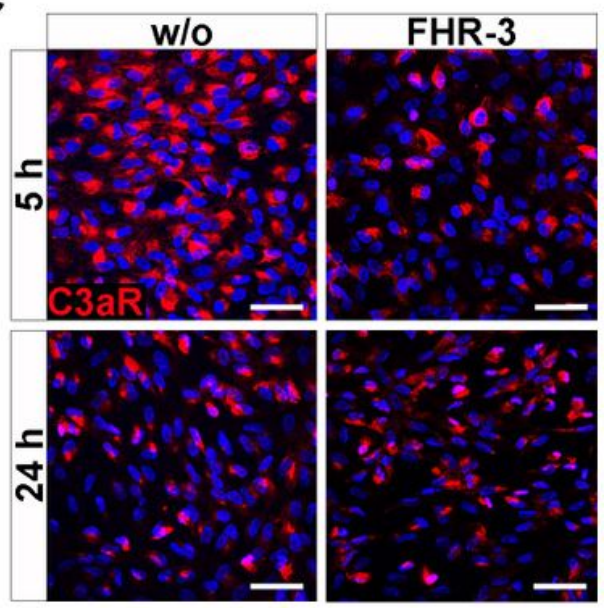

\section{Figure 6}

C3aR expression was time-dependently regulated in FHR-3 stressed ARPE-19 cells. (A) C3AR expression was decreased after $5 \mathrm{~h}$ and increased after $24 \mathrm{~h}$ FHR-3 incubation. This effect could be confirmed on protein level: (B) Western blots of ARPE-19 cell lysates showed a tendency for decreased C3aR levels (54 $\mathrm{kDa}$ ) $5 \mathrm{~h}$ after FHR-3 treatment. (C) Decreased C3aR protein levels were detected by immunohistochemistry using a specific anti-C3aR antibody (red) after 5 h FHR-3 incubation (upper panels), whereas no differences between FHR-3 stressed and unstressed controls were observed after 24 $\mathrm{h}$ (lower panels). Scale bars $40 \mu \mathrm{m}$. w/o untreated control (dotted line). Mean with standard deviation is shown. ${ }^{*} \mathrm{p}<0.01$. (A) two-tailed, unpaired t-test, Mann-Whitney test $(n=3) ;(B)$ Kruskal-Wallis test, Dunn's multiple comparison test $(n=2)$.
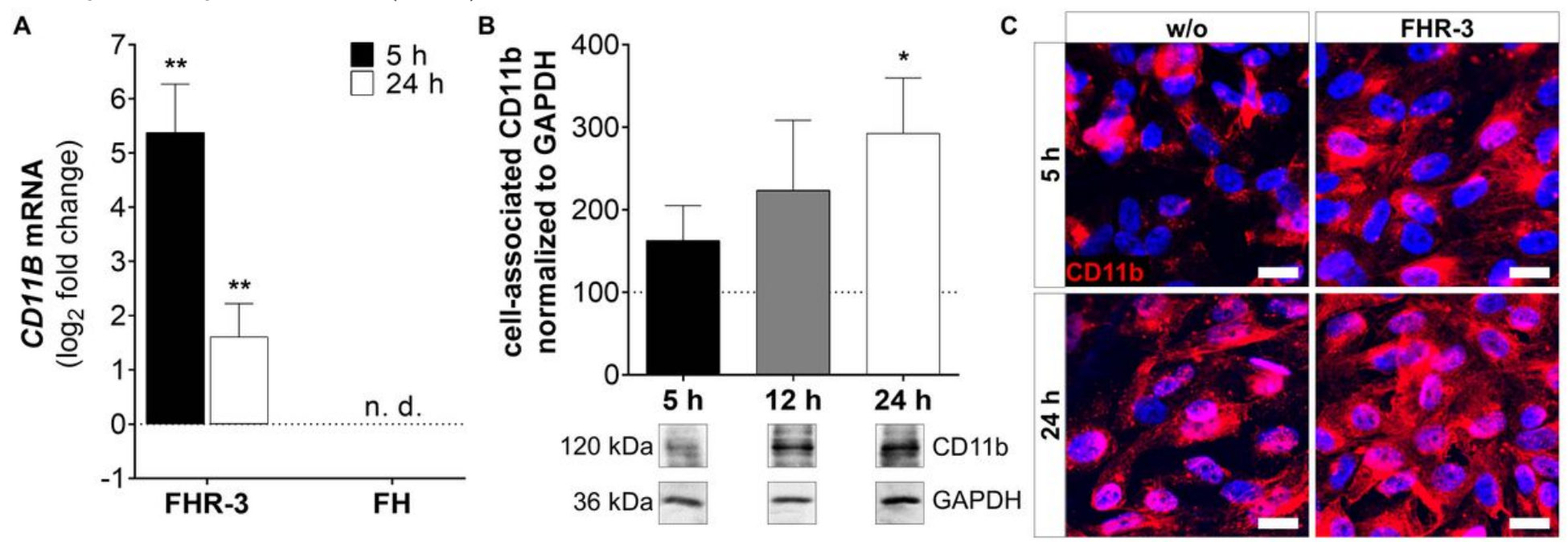

Figure 7

CD11b expression was highly elevated in FHR-3 treated ARPE-19 cells. (A) CD11B expression was highly elevated after $5 \mathrm{~h}$ and $24 \mathrm{~h}$ FHR-3 incubation. No expression of CD11B mRNA could be detected when cells were treated with FH. The effect of FHR-3 could be confirmed th the protein level: (B) Western blots of ARPE-19 cell lysates showed a time-dependent increase in CD11b levels (120 kDa) from $5 \mathrm{~h}-24 \mathrm{~h}$ after FHR-3 incubation. (C) Elevated CD11b protein levels were detected by immunohistochemistry using 
a specific anti-CD11b antibody (red) after $5 \mathrm{~h}$ and $24 \mathrm{~h}$ of FHR-3 incubation (right panels). Scale bars 40 $\mu \mathrm{m}$. w/o untreated control (dotted line). n.d. not detected. Mean with standard deviation is shown. ${ }^{*} \mathrm{p}<$ 0.01 , ${ }^{\star} p<0.05$. (A) two-tailed, unpaired t-test, Mann-Whitney test $(n=3)$; (B) Kruskal-Wallis test, Dunn's multiple comparison test $(n=2)$.
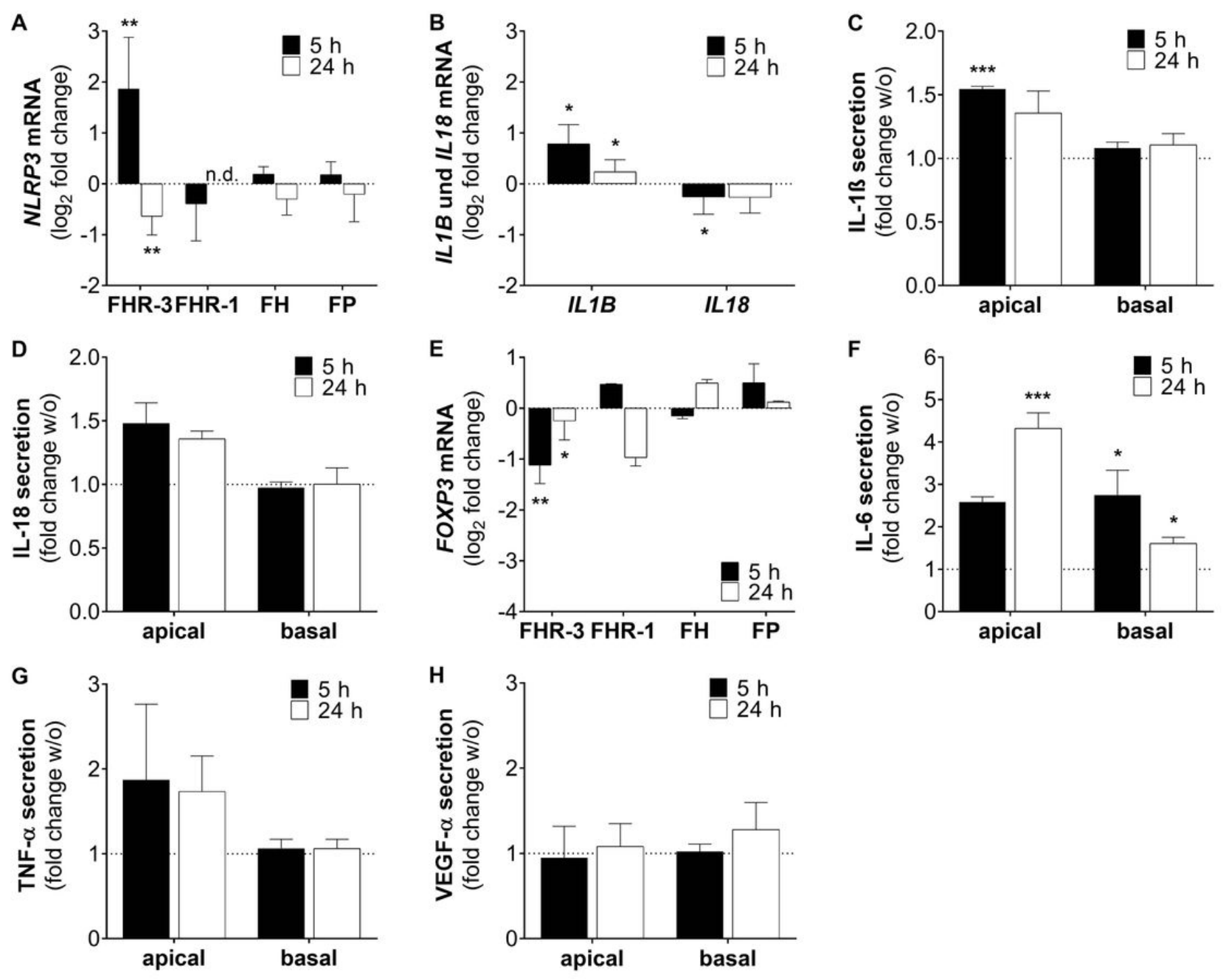

\section{Figure 8}

FHR-3 induced an ARPE-19 cell dependent pro-inflammatory micro-environment. (A) NLRP3 expression in ARPE-19 cells was either increased or decreased after $5 \mathrm{~h}$ or $24 \mathrm{~h}$ FHR-3 treatment, respectively. This was in contrast to no expression changes following FHR-1, FH or FP incubation. (B) Transcripts of IL1B were significantly elevated, whereas IL18 expression was slightly decreased after FHR-3 treatment. (C, D) Apical secretion levels of (C) IL-1ß and (D) IL-18 were increased in ARPE-19 cells after FHR-3 stress. (E) FOXP3 mRNA expression was reduced $5 \mathrm{~h}$ and $24 \mathrm{~h}$ after FHR-3 incubation. (F) Secretion of IL-6 was significantly raised after FHR-3 incubation, both on the apical and basal cell site. (G) ARPE-19 cell secretion of TNF-a was tendentially increased after FHR-3 incubation on the apical site compared to w/o. (H) VEGF-a was secreted by ARPE-19 cells, but showed no differences between FHR-3 treated and 
untreated cells. w/o untreated control (dotted line). n.d. not detected. Mean with standard deviation is shown. ${ }^{* \star} p<0.001,{ }^{* \star} p<0.01,{ }^{*} p<0.05$. two-tailed, unpaired t-test, Mann-Whitney test $(n=3)$.

A

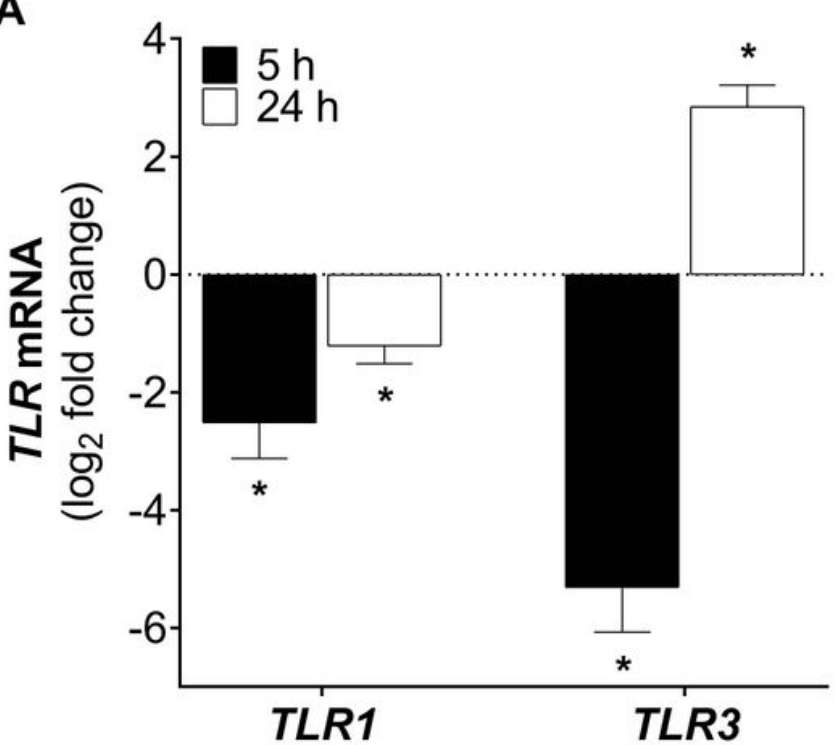

B

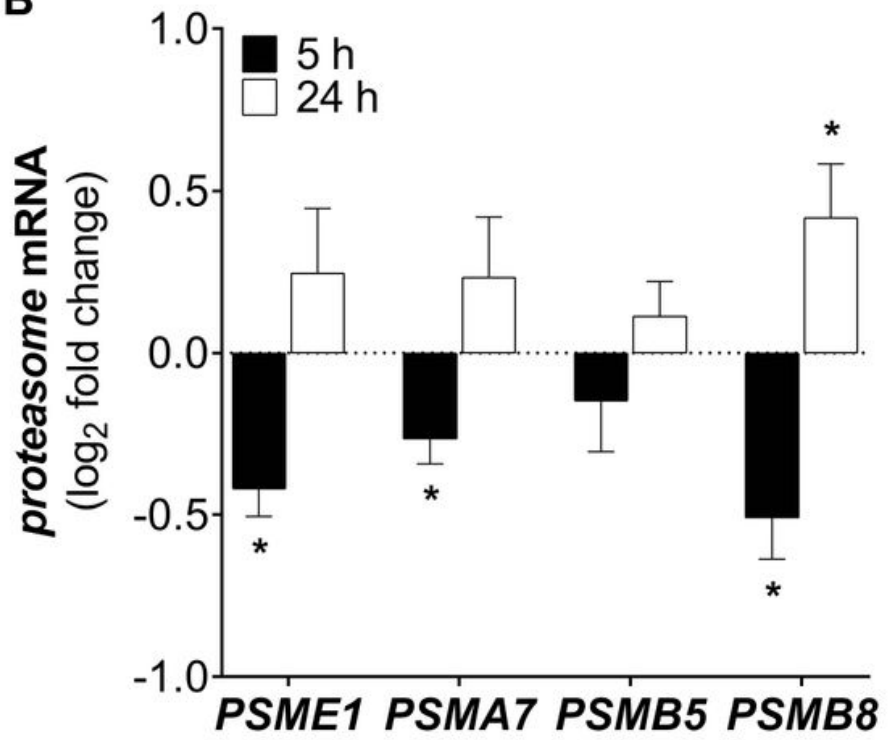

Figure 9

FHR-3 altered cellular toll-like receptor and proteasome marker expression in ARPE-19 cells. (A) TLR1 expression was downregulated $5 \mathrm{~h}$ and $24 \mathrm{~h}$ after FHR-3 cell stress, whereas TLR3 transcripts were downregulated after $5 \mathrm{~h}$ and elevated after $24 \mathrm{~h}$ of FHR-3 incubation. (B) Proteasome marker transcripts (PSME7, PSMA1, PSMB5, PSMB8) were time-dependently regulated after FHR-3 incubation (5 h decreased and $24 \mathrm{~h}$ increased). Dotted line untreated control. Mean with standard deviation is shown. ${ }^{*} \mathrm{p}$ $<0.05$. two-tailed, unpaired t-test, Mann-Whitney test $(n=3)$.

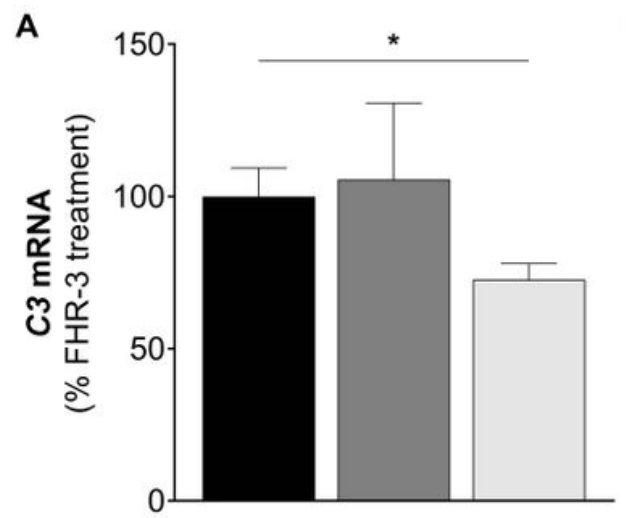

FHR-3
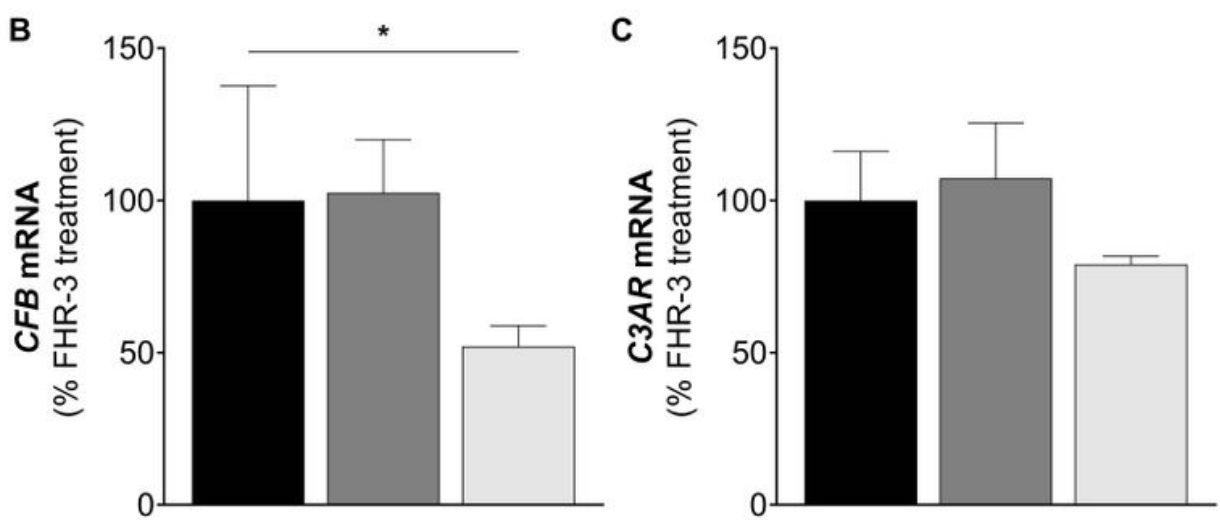

FHR-3 + control-ximab

FHR-3 + RETC-2-ximab

\section{Figure 10}

RETC-2-ximab ameliorated the effect of FHR-3 on ARPE-19 cells. ARPE-19 cells were treated with either FHR-3 (black), FHR-3 and control-ximab (dark grey) or FHR-3 and RETC-2-ximab (light grey). (A) C3 mRNA expression was reduced by $27 \%$, (B) CFB mRNA expression was reduced by 48 \%, and (C) C3AR mRNA 
expression was reduced by $21 \%$ when incubated with FHR-3 and RETC-2-ximab compared to FHR-3 alone. Shown is the relative mRNA expression to FHR-3 treated cells in \%. Mean with standard deviation is shown. ${ }^{\star} p<0.05$. Two-tailed, unpaired t-test with Welch's correction $(n=2)$.

\section{Supplementary Files}

This is a list of supplementary files associated with this preprint. Click to download.

- graphicalabstract.jpg

- supplement210311JNI.docx 